\title{
Nip the HPV encoded evil in the cancer bud: HPV reshapes TRAILs and signaling landscapes
}

\author{
Talha Abdul Halim', Ammad Ahmad Farooqi ${ }^{i^{*}}$ and Farrukh Zaman ${ }^{1}$
}

\begin{abstract}
HPV encoded proteins can elicit ectopic protein-protein interactions that re-wire signaling pathways, in a mode that promotes malignancy. Moreover, accumulating data related to HPV is now providing compelling substantiation of a central role played by HPV in escaping immunosurveillance and impairment of apoptotic response. What emerges is an intricate network of Wnt, TGF, Notch signaling cascades that forms higher-order ligand-receptor complexes routing downstream signaling in HPV infected cells. These HPV infected cells are regulated both extracellularly by ligand receptor axis and intracellularly by HPV encoded proteins and impair TRAIL mediated apoptosis. We divide this review into different sections addressing how linear signaling pathways integrate to facilitate carcinogenesis and compounds that directly or indirectly reverse these aberrant interactions offer new possibilities for therapy in cancer. Although HPV encoded proteins mediated misrepresentation of pathways is difficult to target, improved drug-discovery platforms and new technologies have facilitated the discovery of agents that can target dysregulated pathways in HPV infected cervical cancer cells, thus setting the stage for preclinical models and clinical trials.
\end{abstract}

\section{Introduction}

There is an overwhelming list of research work that underlines the fact that HPV encoded proteins control cell cycle progression, apoptosis and cell differentiation, and have emerged as fundamental regulators of cervical cancer. Recent studies have revealed a complex network of protein interactions in HPV infected cells, and have connected HPV encoded proteins with other key signaling pathways. Such crosstalk has uncovered novel roles for signalings, including regulation of TGF $\beta / S M A D$, WNT/ $\beta$-catenin and Notch signaling cascades by HPV encoded proteins during carcinogenesis. This review highlights recent findings and trends in the HPV infected cervical cancer with an emphasis on how the HPV encoded proteins integrate with other pathways to promote cervical cancer. Moreover, several clues related to role of TRAIL mediated signaling in HPV infected cervical cancer cells are discussed. It also provides a better understanding of role of miRNAs in HPV infected cervical cancer cells. We also review recent patterns and approaches which have been used to induce apoptosis in

\footnotetext{
*Correspondence: ammadahmad638@yahoo.com

${ }^{2}$ Laboratory for Translational oncology and Personalized Medicine, RLMC, 35 Km Ferozepur Road, Lahore, Pakistan

Full list of author information is available at the end of the article
}

HPV infected cervical cancer cells. Oncogenic proteins, such as those encoded by HPV, frequently form ectopic signaling complexes to re-constitute cellular behavior and exemplify how improved understanding of the HPV associated mechanisms might be translated into clinical benefit.

Histological studies provide classification of cervical cancer. Therefore it can be characterized into different sub-categories, including squamous cell carcinomas (SCC) and adenocarcinomas (AdCAs). SCCs develop via welldefined precursor stages, called cervical intraepithelial neoplasia (CIN, graded 1-3), however precursor stages for AdCAs are less well characterized. The precursor lesions to cervical cancers are known as cervical intraepithelial neoplasia (CIN) and noatably CIN1 lesions are referred to as low-grade CIN whereas CIN2 and 3 lesions together are considered high-grade CIN $[1,2]$.

Epidemiological and experimental studies have provided considerable verification that persistent infections with high-risk types of HPV (hrHPVs; HPV16, 18, 31, 33, 45) are causative agents of cervical cancer [3]. Increasing sophisticated information has enhanced our knowledge related to HPV-16 genome. It is a well established fact that HPV-16 genome is organized into six early (E1, E2, E4, E5, E6, and E7) and two late (L1 and L2) open reading 
frames that code for functional and structural proteins, respectively. There is a categorization based on functions of the proteins as E1 and E2 are necessary for replication of the viral genome, E6 and E7 are responsible for maintaining the correct environment for DNA replication in the host cell by preventing possible cell cycle arrest and intrinsic p53-dependent apoptosis [4-6].

Accumulating evidence on cellular receptor-binding and internalization pathways of HPVs is providing further insights into the function of the pathways involved, their constituent proteins and ways in which they gain entry into host cells. There are wide-ranging pathways which are documented to be used by HPV including clathrin-mediated endocytosis, caveolar endocytosis, clathrin- and caveolae-independent pathway. Details can be found elsewhere $[7,8]$. It has previously been speculated that virus enters into host cell simplistically however it is now evident that HPV interacts with different molecules extracellularly for rapid activation of signaling pathways important for infection. It has been experimentally verified that HPV interaction with syndecan-1 via HSPG and binding of syndecan-1 to laminin 332 and $\alpha 6 \beta 4$ integrin are in accordance with the notion that HPV particles colocalize and interact with each of these extracellular molecules [9]. Similarly, CD151-associated integrins ( $\alpha 3 \beta 1$ and $\alpha 6 \beta 1 / 4)$ also regulate HPV16 infection [10]. HPV16 E6 activated mTORC1 by enhanced signaling through miscellaneous receptors, including EGFR, Insulin Receptor and insulin-like growth factor receptors. It was shown that there was a prolonged internalized receptor and a gradual decline in cell surface appearance of those receptors [11]. It has been reported that HPV16 infection is lowest in $\alpha 6$ integrin null cells and experimental methodologies have revealed that Focal Adhesion Kinase (FAK) is the protein activated upon integrin binding. HPV16 induces FAK-Tyr397 phosphorylation in cancer cells and it is intriguing to note that targeted inhibition of $\alpha 6$ integrin function prevents FAK-Tyr397 phosphorylation [12]. In line with the same concept it is appropriate to mention that $\alpha 2 \beta 1$ integrin promotes tumor metastasis in HPV-induced squamous cancer, probabilistically by promoting migratory and invasive potential of cells [13]. However molecular mechanisms are not studied in detail in cervical cancer cells. Overview of HPV entry into cervical cells is shown in the Figure 1.

Studies of cervical neoplasia suggest that HPV infection alone is not responsible for tumor development

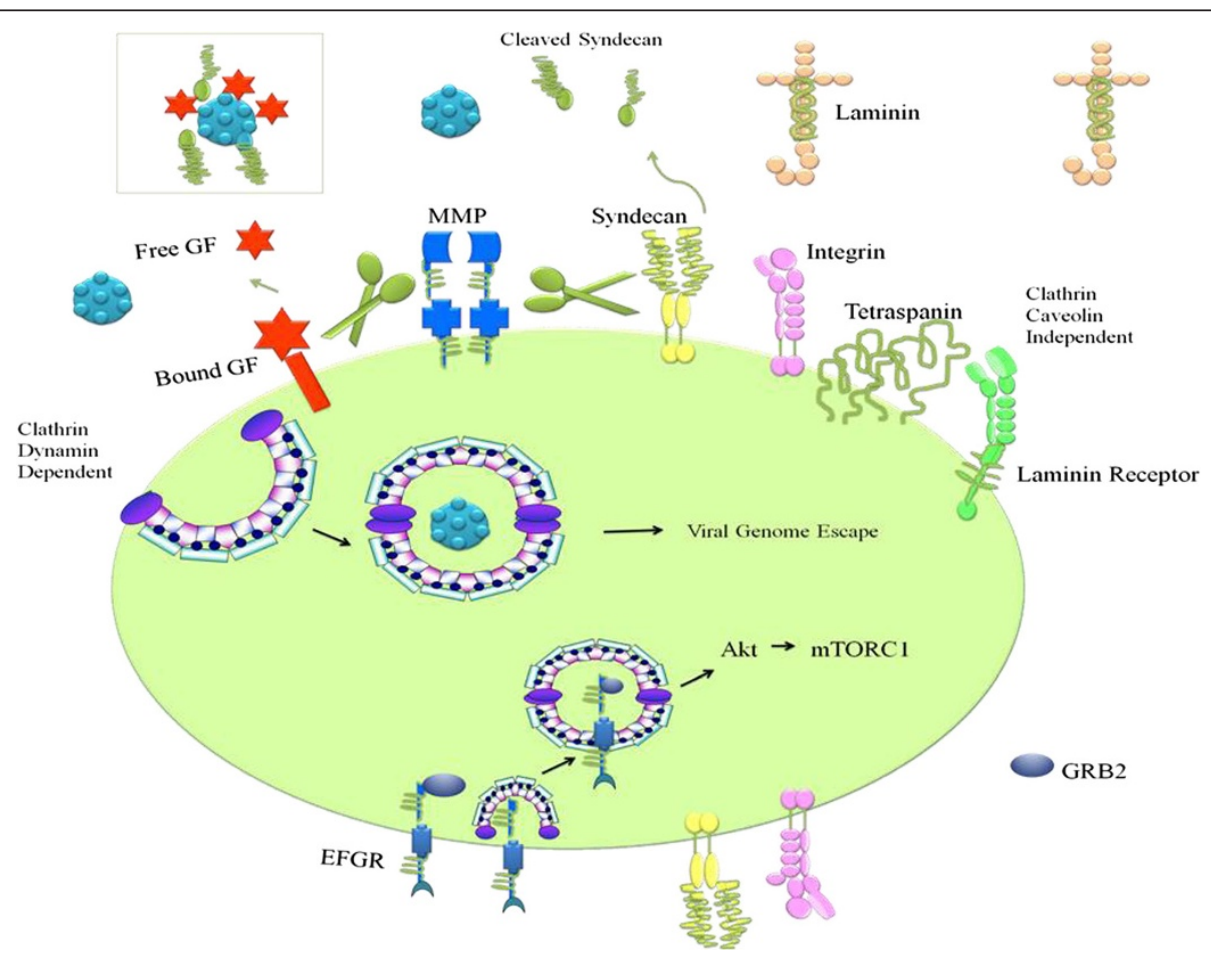

Figure 1 Heparan sulfate proteoglycans (HSPGs) are primary attachment molecules for entry of Human Papilloma Viruses into cells. Syndecans are cell surface heparan sulfates. Laminin undergoes proteolytic processing and can interact with different cell surface receptors including integrin, syndecan and laminin receptor. CD151 is a member of the tetraspanin group of transmembrane proteins and can interact with different integrin a subunits, including a3, a6, and a7. EGFRs are internalized and there is a prolonged receptor mediated signaling in HPV infected cells. Matrix Metalloproteinases proteolytically cleave bound growth factors and syndecans. These cleaved moieties bind to HPV and this complex can interact with different receptors to gain entry into the cervical cells. 
rather Common Fragile Sites (CFSs) are preferential targets for HPV integration in cervical tumors. Convincing substantiation of this relationship was first provided when the sequence of the FRA3B region at 3p14.2 and cellular sequences flanking an HPV16 integration in a cervical tumor were indicated to be identical [14]. It has also been documented that HPV16 integration in CFS results in loss of tumor suppressor genes [15]. E7 oncoprotein interacts primarily with the pATM and it is appropriate to mention that ATM pathway is utilized by HPVs to promote viral replication in differentiating cells [16]. However there is a conflicting report that suggested that ATM mediated signaling induced cell cycle arrest in cervical cancer cells. Furthermore, cervical cancer cells treated with isoliquiritigenin (ISL) displayed an activated ATM that activated its downstream effectors. In addition there was considerably enhanced ratio of pro-apoptotic proteins Hsu et al, [17].

Sp1 DNA binding sites are present within HPV promoters and play an active role in HPV gene expression. Cells expressing HPV promoter luciferase reporter vector treated with nordihydroguaiaretic acid plant lignan derivatives displayed remarkable repression of HPV encoded genes [18].

It is of particular significance that HPV 16 E5 oncogene is a small, highly hydrophobic protein of 83 amino-acids that localizes in endocellular membrane and undergoes homo-oligomerization. This process of oligomerization creates a hydrophilic pore that allows passage of small molecules and ions through these channels [19]. It has been experimentally verified that HPV16 E5 interferes with degradative and recycling endocytic pathways of receptors. E5 protects degradation of receptors by inhibiting the recruitment of Grb2-Cbl complexes responsible for receptor ubiquitination and degradation [20]. It is persuasive to note that E5 regulates the expression of IFN- $\beta$ via IRF1 and knockdown of IRF-1 expression in E5-expressing cells abolishes IFN- $\beta$ expression. Astonishingly, stimulation of IRF-1 expression by HPV16 E5 occurs through E5 mediated activation of NF- $\mathrm{\kappa B}$ that moves into the nucleus to attach to consensus sequences on the IRF-1 gene promoter [21].

Autophagy or "self-eating" is an important mechanism and it has been shown that cellular decisions to autophagy manipulation are modulated by HPV. Cells infected with HPV16 displayed activated PI3K/Akt/mTOR pathway that inhibited autophagy [22]. RECK is a membrane bound protein and is a negative regulator of MMPs. However it has been shown that E6 and E7 downregulate RECK and promote activity of MMP9. One possible mechanism could be miRNA mediated control of RECK in cervical cancer cells [23]. Structural studies provide reasonable evidence that conserved regions of E7 are involved in interaction with different proteins.
Transcriptional co-activator p300, which contains an intrinsic HAT activity, is essential for wide ranging biological functionalities is reported to be regulated by E7 via its CR1 and CR2 domains [24]. Similarly, E7 interacts with pRb through its CR2 and CR3 domains [25]. TBX2 and TBX3 are members of the T-box family of transcription factors and have been reported to repress transcription from the LCR via interaction with HPV16 L2. CHIP analysis provided strong evidence of colocalization of L2 and TBX2 in HPV16 positive CIN I-II tissue sections [26].

ChIP assay confirm that HPV-18 E2 binds the hTERT promoter region via $\mathrm{Sp} 1 \mathrm{in}$ vivo and represses the expression of hTERT. However, HPV-16 E2 stimulates the hTERT expression [27,28]. E5 is interconnected with downregulation of antigen presentation by HLA class I molecules, a protective mechanism that promotes HPVs ability to evade immune clearance through cytotoxicT-lymphocyte (CTL)-mediated adaptive immunity. E5 restricts HLA-A and -B molecules in the golgi apparatus thus repressing their cell surface appearance [29]. Similar mechanisms are opted by HPV to regulate CD1d, an (MHC) class I-like glycoprotein. Cellular studies suggest that E5-expressing epithelial cells retain CD1d in the ER via interfering with the modification of HLA class I heavy chains that characteristically takes place in the ER. E5 has been documented to interact with calnexin in the ER thus compromising calnexin-mediated CD1d folding and impairing trafficking of CD1d to the surface of HPVinfected cells [30].

HPV encoded E5 protein utilizes cAMP/PKA/CREB pathway to stimulate the expression of Prostaglandin E2 (PGE2) receptor [31]. One of the best-characterized biological effects of 16E5 is ERK activation and it has additionally shown that ERK specific phosphorylation sites are present in E1-E4 protein. Predominantly, phosphorylation at threonine 57 enhances keratin binding and provides protection against proteasomal degradation [32]. It has previously been reported that HPV 16E1-E4 protein induces G2 arrest. It was further underscored that arrest does not result from inhibition of the kinase activity of the Cdk1/cyclin B1 complex rather due to retention of active Cdk1/cyclin B1 complexes in the cytoplasm away from their nuclear substrates [33].

Spindle assembly checkpoint (SAC) is a 'wait-anaphase' mechanism that has evolved in eukaryotic cells and spindle checkpoint proteins (SCPs), sense the existence of misaligned sister chromatids during mitosis and meiosis. HPV16/18 E5 expressing cells have considerably reduced expression of Bub1 and Mad2 [34]. NIH 3T3 cells transfected with the HPV 16 full-length genome and mimetic miR-125b displayed drastic decrease in viral DNA and protein synthesis however, co-transfection with antimiR-125b and HPV 16 markedly increased HPV DNA 
[35]. miR-125b also promotes cell death by negatively regulates spindle assembly checkpoint gene MAD1 [36].

Various splicing factors including ASF/SF2 are overexpressed in high-grade cervical lesions and cervical cancer. It was indicated that E2 caused a three- to fourfold upregulation of SF2/ASF [37]. Using experimental techniques it has been identified that 3'-splice site on the HPV-16 genome, is used to produce primarily E4, E6, and E7 mRNAs and is regulated by ASF/SF2. More specifically, splice site is followed by 15 potential binding sites for the splicing factor ASF/SF2 [38]. Rapidly increasing research on post-transcriptional regulation of HPV 16 indicates that hnRNPA1 and hnRNPA2 promote HPV16 E6 exon exclusion, whereas Brm and Sam68 mediate exon inclusion [39]. It has also been suggested that hnRNP A1 binding to the HPV-16 late 3' splice site prevents the interaction of the splice site with the U2AF35/ U2AF65 factors, thus inhibiting splicing [40].

Laboratory analysis of immortal human cell lines transfected with E6 also suggests that E6 oncoproteins are characterized by the presence of a PDZ (PSD95/Dlg/ZO-1) binding motif in their extreme carboxy termini. PDZ domain-containing cellular substrates, including the cell polarity regulators human Dlg (hDlg) (11) and human Scribble (hScrib) have been identified to be known targets of E6. Furthermore, other E6 PDZ domain-containing targets consist of the MAGI family of proteins, which act as scaffolds in the regulation of tight-junction (TJ) assembly [41]. Moreover there are additional targets which are reported to be regulated by HPV encoded proteins. It is now recognized that human cells express a unique family of sense and antisense mitochondrial ncRNAs. Sense transcript or SncmtRNA (SncmtRNA-1), is expressed in normal proliferating cells and cancer cells. Antisense transcripts (ASncmtRNA-1 and -2) are down-regulated which highlights an important step during neoplastic transformation and progression. Details of mechanism involved reveal that immortalization of HFK with HPV-16 or 18 results in repression of antisense transcript through E2 and stimulation of expression of sense transcript via E6 and E7 [42]. E6 and E7 have also been noted to reduce the expression of the globular heads of the $\mathrm{C} 1 \mathrm{q}$ receptor (gC1qR), a mitochondrial surface protein [43]. HPV16 E6/ E7 are involved in degradation of p130. Recent studies identified that p130 and the related p107 protein are components of a transcriptionally repressive complex termed DREAM (or LINC). In this complex, p130 or p107 are associated with E2F4 or E2F5 and bind to the promoters of genes thus maintaining cell cycle arrest. Sequestration of p130/p107 and E2F4/5 from this complex results is reconstitution of core DREAM proteins via formation of a substitute complex with the B-myb transcription factor that regulates transcription of gene subsets essential for mitosis. Targeted inhibition of HPV16 E6/E7 results in cell- cycle arrest and reformation of the p130-DREAM complex [44].

\section{Signaling cascades in HPV infected cervical cancer cells}

A growing appreciation of misrepresented signaling pathways prompts the realization that spatio-temporal deregulation is likely to contribute broadly to cervical cancer development and may affect the sensitivity and resistance of cancer to targeted therapies. Tremendous experimental work has been done in improving our knowledge that cervical cancer arises from abnormal decision making by cancer cells. These decisions related to cell death or survival are made by molecular signaling networks that process information from outside and from within the HPV infected cervical cancer cells and initiate responses that determine the cell's survival. We dissect this segment of discussion into subheadings that describe regulation of linear signaling cascades in HPV infected cells.

\section{TGF signaling}

Several hints have emerged that indicate that cervical cancer is associated with loss of TGF- $\beta$ responsiveness (gradual decline in TGF receptors) and because cervical epithelial differentiation is altered by E7. For a better understanding of the underlying mechanisms, status of TGF- $\beta 2$ and TGF- $\beta$ RII expression was examined in transgenic mice expressing the oncogene E7 of HPV16 under control of the human Keratin-14 promoter (K14E7 transgenic mice). The results indicated that there was an overexpression of TGF- $\beta 2$ and decrease of TGF- $\beta$ RII expression in this particular model of cervical carcinogenesis [45]. HPV mediates TGF $\alpha$ induced c-fos/c-jun heterodimer formation to regulate expression of oncogenes Figure 2 [46]. Surprisingly, there is a research work that illustrates that E6 and E7 encoded by HPV-16 induce activation of TGF beta1 promoter [47]. It was additionally indicated by a contemporary study that inhibition of E7 expression lowered the expression level of TGF-beta1 and induced apoptosis [48]. Detailed structural insights identified that a 9-bp sequence, GGGGCGGGG, representing the consensus Sp1-binding site between -109 and -100 of the TGF-beta 1 promoter, was the major target for E6-mediated transactivation [49]. There is progressive loss of HPV-16 E2 which is higher in CIN3 than in CIN1 or CIN2, and there is a correlation between loss of HPV-16 E2 expression and loss of TGF-beta1 at the lesion site [50]. TGF-beta1 signaling cascade is involved in induction of chromosomal instability in HPV positive cervical cancer cells and inhibition of TGF-beta1 signaling by an inhibitor of TGFRI prevented telomere-mediated chromosomal instability [51].

Overexpression of SMAD2/3 may be involved in the genesis of cervical cancer Figure 2 [52]. However this 


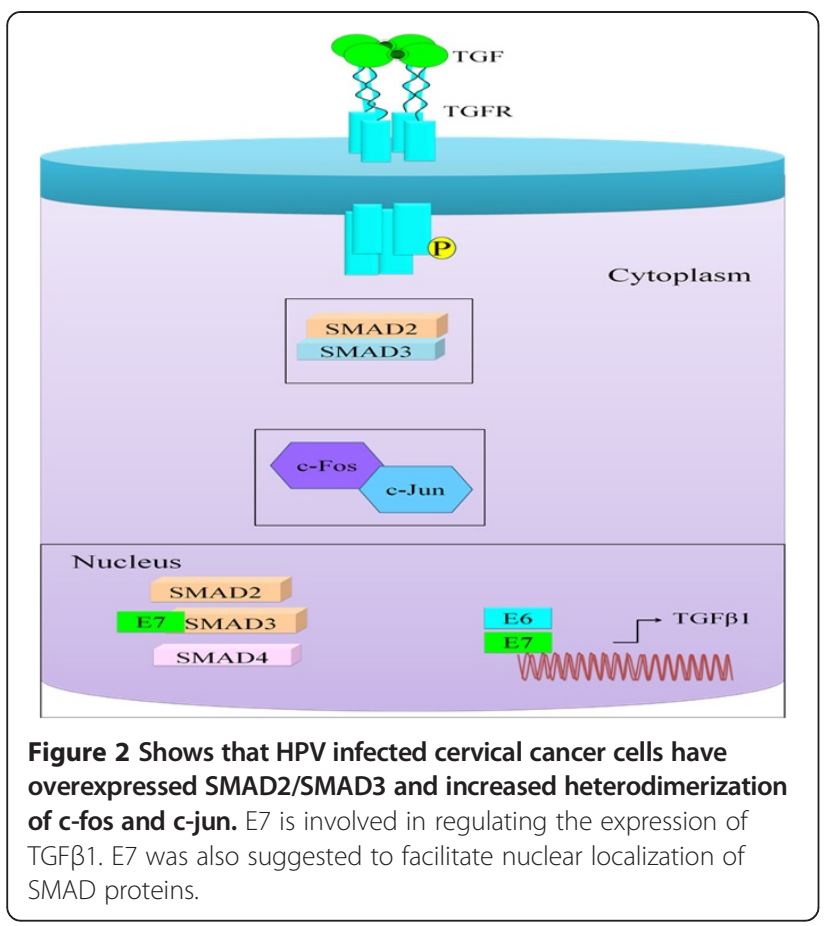

report is in contradiction to another finding that suggested that weak cytoplasmic SMAD4 staining and the absence of Smad4 nuclear staining was associated with poor survival in cervical cancer patients [53]. E7 facilitated the nuclear translocation of Smad proteins (SMAD 2, SMAD3 and SMAD4) in a ligand-independent manner. More intriguingly, E7 interacted with MH1 Domain of SMAD3 to repress TGF- $\beta$-mediated transcription Figure 2 [27,28]. It is necessary to have a better knowledge of regulation of SMAD subsets by HPV encoded proteins in cervical cancer cells. How these SMAD proteins are degraded or rescued in HPV infected cancer cells to regulate cancer progression still is incompletely understood. SMAD7 heterozygous, silent $G$ to $C$ variant in codon 391 was reported in HPV positive and negative cervical cancer samples. However this report did not identify a relationship between SMAD7 mutation and carcinogenesis [54].

However there is a direct piece of evidence that indicates that TGF-beta1 and IL-4 repress HPV-16 oncogene transcription [55]. Enforced expression of nuclear factor I in TGF-beta-sensitive HPV16-immortalized human keratinocytes (HKc/HPV16) inhibited TGF-beta mediated repression of E6 and E7 [56]. Experiments on transgenic mice provided evidence that HPV-11 transformed xenografts showed up-regulation of TGF beta 1 expression and down-regulation of the expression levels of bcl-2, c-myc, c-Ha-ras, c-jun and NFkB $[57,58]$. It is noteworthy that HPV-16 transformed cells show down-regulation of bcl-2 and NFkB as well as NFkB function upon TGF beta 1 treatment $[57,58]$.
It still is confusing whether TGF signaling initially acts as a barrier to HPV encoded proteins associated activities. Putting pieces of evidence together indicate contradictory roles of TGF signaling. It appears that TGF signaling is induced in HPV infected cervical cancer cells however other research findings reveal that HPV encoded proteins degrade SMAD proteins to repress TGF signaling. Cervical carcinogenesis was noted in HPV infected cells both in absence and presence of TGF signaling. In depth studies are required to provide a detailed mechanism.

\section{Wnt signaling}

Interestingly, high-throughput technologies, including the analyses of protein networks have considerably enhanced our current understanding that binding of WNTs to frizzled (FZD) and LRP5 or LRP6 co-receptors transduces a signal across the plasma membrane that results in the activation of the Dishevelled (DVL) protein. Activated DVL inhibited the destruction complex and facilitated accumulation of CTNNB1 in the nucleus where it acted as a co-activator for Wnt target genes. Results obtained through immunohistochemistry revealed that normal cervical epithelium showed staining of $\beta$-catenin only on the membrane. However, cytoplasmic and nuclear staining was observed only on the basal proliferating layer of the normal stratified squamous epithelium. There is further elaboration of Wnt signaling mediated biological implications and it is clear that activation and stabilization of the catenin is controlled by HPV encoded proteins and various other oncogenes. SV40 small $\mathrm{t}$ antigen (smt) was reported to stabilize catenin by inhibiting PP2A [59]. Moreover it is also suggested that HPV encoded proteins stabilize catenin by suppressing SIAH-1. SIAH-1 is a target gene of p53 which is degraded by HPV encoded proteins and targeted inhibition of HPV encoded proteins resulted in restoration of SIAH. Genetic and biochemical data have demonstrated that E6 and E7 facilitated beta-catenin nuclear accumulation [60].

These finding indicated that there is an activated Wnt/ $\beta$-catenin signaling cascade in HPV-associated premalignant lesions that plays an efficient role in accelerating cervical carcinogenesis. Activation of the Wnt pathway acted as secondary events that are necessary for malignant transformation of HPV-infected epithelial cells [61]. It is also relevant to mention that negative regulators of Wnt signaling are epigenetically repressed and a recent report clarifies an association between DKK3 and SFRP2 promoter methylation in cervical cancer [62].

\section{Notch Signaling}

As discussed in the introductory section that E2 functions as a repressor of the viral upstream regulatory region 
(URR) promoter that drives transcription of the E6 and E7 oncogenes, therefore loss of E2 is a prerequisite for increased E6/E7 expression. To identify whether the inhibition of E6/E7 expression by activated Notch1 occurs at the level of URR promoter activity, HeLa cells were transiently transfected with a plasmid for the URR promoter and an expression vector for activated Notch1. It was noted that URR promoter activity was significantly reduced by cotransfection of the activated Notch1 expression. Additionally it was observed that Notch-1 repressed URR by inhibiting AP-1. Notch1 inhibited c-Fos protein and simultaneously enhanced another Fos family member, Fra-1. Fra-1 lacked a transcription activating domain and acted as a suppressor rather than an inducer of AP-1dependent transcription [63].

The data gained through electrophoretic mobility shift assays indicated that Notch overexpression was correlated to altered AP-1 DNA binding activity and complex composition. After inducing a moderate level of Notch expression, an increased DNA binding was demonstrated byAP-1. However cells transfected with high expression levels of Notch displayed a decrease in cFos signal and an increase in Fra1 signal [64]. It is convincing to note that explants of $\mathrm{HaCaT}$ cells co-expressing Jagged1and E6/E7 generated tumors greater than $90 \mathrm{~mm}$. However, coexpression of Delta1 and E6/E7 generated lesions of less than $10 \mathrm{~mm} 3$. It was noted that Jagged-1 and E6/E7 coexpressing cancer cells used PI3K/Akt signaling axis to induce EMT [65]. More detailed insights suggest that Jagged-1 induced HES-1 that repressed Manic Fringe (negative regulator of Jagged-1 mediated signaling). These HES1 binding sites were found at nucleotide position -250 upstream of the transcriptional start site of Manic Fringe [66]. Notch-1 is also indicated to behave differently as HPV infected cells use Notch-1 during the progression from cervical intraepithelial lesions (CIN) to invasive cervical carcinoma [67].

\section{Inducing apoptosis in HPV positive cancer cells}

Cellular and molecular studies have outstandingly clarified existing concepts of role of HPV in cervical cancer. It is now evident that HPV oncoproteins transform noncancerous epithelial cells into cancerous carcinomas by targeting key tumor suppressors and pro-apoptotic proteins and additionally impair tumor suppressor and apoptotic pathways. Therefore multi-targeted approach based on targeting of HPV encoded proteins and misrepresented pathways has shown promise in restoring apoptotic pathway. We subdivide next coming section into generalized approaches in inducing apoptosis in HPV infected cervical cancer cells and TRAIL mediated signaling in HPV infected cervical cancer cells. Treating cervical cancer cells with Withaferin A resulted in downregulation of HPV-E6 and E7 oncoproteins [68]. A recent report adds a new dimension to role of HPV$16 \mathrm{E} 6$ in cervical cancer cells. It is intriguing to note that enforced expression of 16-E6 in cervical cancer cells stimulated the expression of p53 and induced apoptosis [69]. Interestingly, leaf extract of Bryophyllum pinnata was effective in repressing HPV18 transcription. It also suppressed oncogenic c-Fos and c-Jun expression [70]. $\mathrm{n}$-Hexane and chloroform extracts of Anisomeles malabarica induced death in HPV16-positive cervical cancer cells [71].

\section{TRAIL mediated apoptosis}

Progressively there is a significant accumulation of research reports which have categorized HPV encoded proteins as oncogenes that suppress apoptosis. In the upcoming section we dissect viral encoding genes which have been experimentally investigated regarding their roles in cervical cancer progression and underlying mechanisms which induce resistance against TRAIL mediated apoptosis.

Cellular studies indicate that TRAIL binds to several distinct receptors and it is a well established piece of information that DR4 and DR5 contain the intracellular death domain (DD) essential for the induction of apoptosis following receptor ligation. Contrary to this, DcR1 nor DcR2 are unable to induce apoptosis due to a complete or partial lack of the intracellular DD, respectively. Using high-throughput technologies, we are able to understand that binding of TRAIL to TRAIL-R1 or TRAIL-R2 induces trimerization of TRAIL-R1 or TRAIL-R2, and FADD binds to the trimerized TRAILR1 or TRAIL-R2 death domains. Then, FADD acts as an adaptor molecule that is involved in signal dissemination by recruiting caspase 8 , which initiates a proteolytic cascade involving other caspases eventually leading to cell death [72]. TRAIL mediated signaling is shown in Figure 3.

It has lately been shown that pretreating HPV16 E7 expressing cervical cancer cells with HDAC inhibitors considerably sensitized cells to TRAIL. c-FLIP suppression by HDAC inhibitors restores death receptormediated apoptosis in HeLa cells. HDAC inhibitors target anti-apoptotic proteins and induce TRAIL mediated apoptosis in resistant cancer cells by enhancing surface expression of TRAIL receptors and re-distribution of TRAIL receptors into lipid rafts (reviewed by [73]). It has previously been shown that E7 oncoprotein binds to multiple functional partners, particularly $\mathrm{pRB}$ and HDAC1 and HDAC2 [74]. However, targeted inhibition of HPV16- E7 abolished HDAC inhibitors mediated sensitization to TRAIL [75]. There is a contradictory report that indicates that E6/E7-siRNA induces senescence rather than apoptosis in $\mathrm{SiHa}$ cells [76]. Increasing 


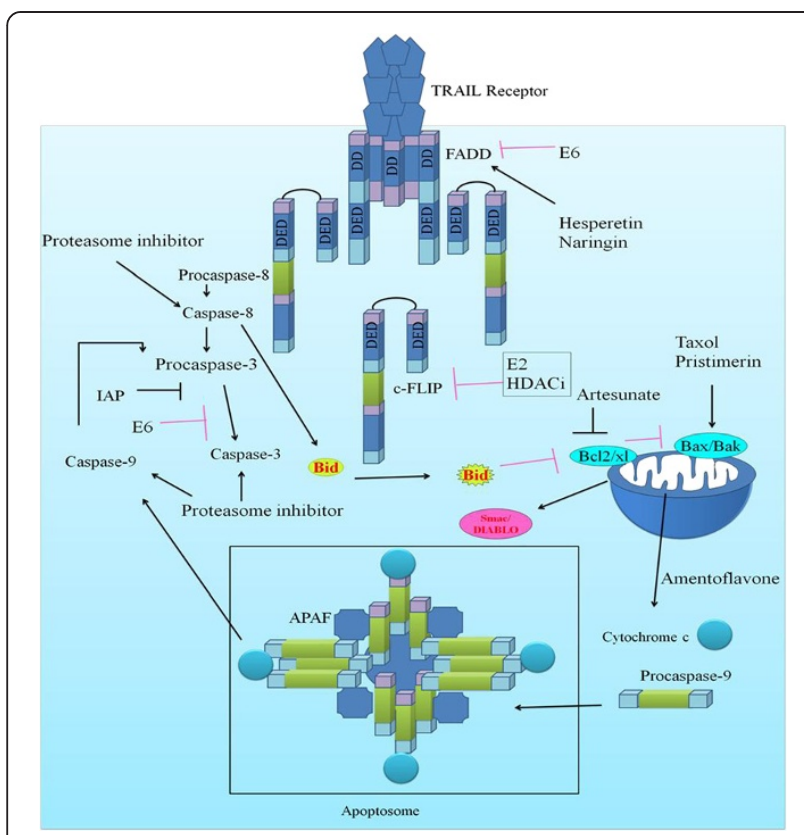

Figure 3 Shows regulation of pro-apoptotic and anti-apoptotic proteins by HPV encoded proteins and compounds.

technologies have revolutionized our understanding of the underlying mechanisms which are opted by HPV for the development of cervical cancer, implying that HPVs have evolved immunoevasive mechanisms. It is now known that HPV escapes immunosurveillance by repressing the genes involved in IFN signaling (STAT1), proapoptotic genes (TRAIL), and pathogen recognition receptors (TLR3, RIG-I, and MDA5) [77]. Cells treated with cAMP analog 8-CPT-cAMP (adenylyl cyclase activator), PDE inhibitors (isobutylmethylxanthine) or PKA inhibitors displayed an upregulated expression of Smac/ DIABLO. This observation signifies the fact that cAMP/ PKA/CREB pathway is an important regulator of Smac/ DIABLO transcription [78]. Although it has been shown that HPV encoded E5 protein utilizes CAMP/PKA/CREB pathway to stimulate the expression of genes [31]. It needs to be tested with reference to pro-apoptotic and antiapoptotic gene subsets in cervical cancer cells. E2F1has also been shown to directly bind and activate the promoter of Smac/DIABLO, through the E2F1binding sites [79].

It is surprising to note that HPV-E2 gene disruption is one of the key features of HPV-induced cervical malignant transformation and is tumor suppressing gene encoded by HPV. Laboratory investigations have revealed that HPV16-E2 inhibits c-FLIP and renders cell hypersensitive to apoptotic signal. It was confirmed by overexpressing cFLIP in cancer cells that completely hampered E2 mediated apoptotic response [80-83]. Co- immunoprecipitation and western blot analyses suggest an interaction between HPV 16-E2 and cFLIP isoforms thus inhibiting the recruitment of cFLIP to DISC. Characteristically it has been suggested that targeting of p53 by HPV encoded proteins resulted in transcriptional repression of Puma and abrogation of translocation of Bax to mitochondrial membrane. Puma is a proapoptotic protein that acts as an upstream activator of Bax, by inducing a conformational change thus facilitating the transmigration of Bax from the cytosol to the mitochondrial membrane [84]. Cervical cancer cells treated with cyano analogue of boswellic acid displayed reduced viral E6 mRNA expression and enhanced expression of Puma through p53 pathway [85]. Antisense and peptide aptamers targeting HPV E6/E7 have been shown to induce target cell apoptosis through activation of pRb $[86,87]$. It has also been shown that p53 triggers the expression of pro-apoptotic proteins (Noxa, Puma and Bax) and repressed the expression of pro-proliferative factors CyclinB1, cdc2, and Cdc25c [88]. Moreover there is study that challenges classical concept of $\mathrm{pRb}$ in suppressing cancer via negative regulation of E2F1. It highlights tumor suppressor role of E2F1. E2F1 up-regulates the expression of the pro-apoptotic proteins PUMA, Noxa and Bim. It needs detailed investigation in cervical cancer cells to have a better understanding of the role of E2F1 in cervical cancer progression. Keeping in view tumor suppressor role of E2F1 it will be necessary to identify relationship between $\mathrm{pRb}, \mathrm{E} 2 \mathrm{~F} 1$ and regulation of pro-apoptotic genes [89].

Targeted inhibition of HPV16-E6 resulted in restoration of sensitivity to TRAIL [90]. There is sufficient experimental evidence that transfection of HPV16-E6 gene into cells with wild-type p53, substantially decreased the level of p53 protein, that resulted in suppression of DR4 induction by DNA-damaging agents [91]. Transiently transfecting HPV16-E5 gene into immortalized human keratinocyte cell line $\mathrm{HaCaT}$ severely repressed activation of caspase-3 upon TRAIL and FasL treatment [92]. Confluence of information suggests that HPV degrades p53 that results in suppression of p53 mediated expression of death receptors. However there is a finding that shows that IFN-beta increases TRAIL expression both directly at the mRNA level and indirectly by enhancing surface protein levels [93]. HPV16-E6 positive cervical cancer cells displayed a rapid reduction in the protein levels of both FADD and procaspase 8, which resulted in suppression of the activation of caspases 8,3 and 2 [94]. FZD8 was found to be highly expressed in HeLa cells and in future it would be interesting to note if targeting of FZD8 in cervical cancer cells could be helpful in overcoming resistance against TRAIL [95]. Similar approach has been tested in breast cancer cells and has been shown to be effective [96]. 


\section{Multi-targeted approach in restoring TRAIL mediated apoptosis}

Researchers are targeting the anti-apoptotic machinery and associated signaling cascades that impair TRAIL mediated apoptosis. Wogonin, a flavonoid isolated from the root of the medicinal herb Scutellaria baicalensis Georgi was reported to be useful in sensitizing cervical cancer cells to TRAIL [97]. It has lately been suggested that bortezomib and nelfinavir considerably enhanced the efficacy of an apoptosis-inducing TRAIL receptor antibody [98]. Aspirin and TRAIL significantly repressed ERK1/2 activation and down-regulated Mcl-1 [99]. Various reports suggest that phosphorylated ERK1/2 induces TRAIL resistant phenotype and aspirin has been shown to inhibit pERK1/2. ERK pathway activation increases the expression of prosurvival proteins, particularly Mcl-1, by stimulating de novo gene expression. It is intriguing to note that expression of Mcl-1 in tumor cells can be regulated at the transcriptional level or through post translational modifications by ERK [100]. Artesunate is an anti-malarial drug that is explored to be effective in sensitizing cervical cancer cells to TRAIL mediated apoptosis by suppressing pro-survival proteins, such as survivin, XIAP and Bcl-XL [101]. Noatbly strong synergistic apoptosis-inducing effect of the combination of rhTRAIL and MG132, particularly in CIN II/III lesions indicates that rhTRAIL combined with proteasome inhibitors open new horizons of therapeutic strategies for CIN II/III [102]. Luteolin synergistically acts with rh TRAIL to induce apoptosis in HeLa cells [103]. HPV control of TRAIL mediated signaling is shown in Figure 3.

\section{Stimulating the expression of DRs}

Phenylethyl isothiocyanate (PEITC) increased the expression of the DR4 and DR5 in cervical cancer cells [104]. Likewise, synergistic treatment with taxol and pristimerin induced cervical cancer apoptosis by enhancing intracellular ROS, upregulation of DR5 and activation of Bax [105]. Cisplatin also enhanced DR5 expression in cervical cancer cells [106]. Irradiation cells showed a p53-dependent rise in DR5 membrane expression [107]. It is surprising to note that proteasome inhibitor MG132 substantially stimulated DR4 and DR5 membrane expression in HeLa. However in $\mathrm{SiHa}$ only DR5 membrane expression was upregulated from almost unnoticeable to notable levels independent of p53 [108]. This finding adds a new layer of information that p53 is not indispensible for expression of DR5.

DR5 promoter contains multiple Sp1 binding sites, which may contribute to the increased DR5 expression $[109,110]$. Sp1 binding sites are also present in promoter region of TRAIL gene [111]. It has also been shown that Sp1 is phosphorylated by ERK that enhanced DNA binding affinity of SP1 [112]. DNMT-mediated hypermethylation of promoter regions cause transcriptional repression and it has been shown that epigenetic repression is induced by DNMT in the proximity of the TRAIL promoter [113]. Moreover, H3K27me3 epigenetic mark at the DR5 promoter represses its expression. However it has been indicated that interference strategies directed against Suz12 and Ezh2 promoted DR5 expression [114]. It is also important to mention that in HPV16 E6 and E7 expressing cervical cancer cells have considerably enhanced DNMT activity and there is a transcriptional down-regulation of E-Cadherin in these cells $[115,116]$. It has been shown that JNK is involved in stimulating the expression of DR through CHOP and SP1. Using different kinase inhibitors, including the p42/ 44 MAPK inhibitor PD098059, the p38 MAPK inhibitor SB203580, and the JNK1/2 inhibitor SP600125 it was confirmed that DR5 expression was regulated by JNK. Among the inhibitors tested, the JNK1/2 inhibitor SP600125 effectively impaired DCA-induced DR5 expression, whereas the p42/44 and p38 MAPK inhibitors failed to repress DR5 expression. Cardamonin isolated from black cardamom induces the expression of DRs using CHOP and SP1. The relationship was confirmed by abrogation of CHOP and SP1 that resulted in inhibition of mediated up-regulation of DRs [117]. MEK kinase 1 (MEKK1) is a serine threonine kinase that is activated following etoposide treatment and activates IKK. IKK mediated inactivation of IKB results in sequestration of NF-kappaB from IKB. NFKB translocates into the nucleus to stimulate the expression of DR4 [118]. DR4 is a p53 target gene and is transcriptionally controlled by $\mathrm{p} 53$ through a functional intronic p53 binding site (p53BS) [119]. It is also relevant to mention that cells treated with EGF show a decrease in DR5 expression. Detailed analysis indicates that EGF treatment facilitates co-existence of NFKB with HDAC at the binding site present in intronic region of DR5. However etoposide treatment inhibits NFKB mediated recruitment of HDAC to binding site [120]. Cervical cancer cells treated with naringin displayed increased cell surface appearance of DR and mitochondria-mediated apoptosis in human cervical cancer ( $\mathrm{SiHa}$ ) cells Ramesh et al, [121].

It is becoming successively more understandable that nanoparticles (NPs) have become an important tool in many industries including healthcare. Substantial fraction of information has revealed that compared with free antitumor drugs, drug-loaded long-circulating nanovectors show prolonged circulation time in plasma, enhanced accumulation in tumor tissues, and better-quality therapeutic activity. Functionalizing nanovectors with targeting moieties can promote specific receptor-mediated endocytosis, limiting non-specific uptake into the normal 
tissues. TRAIL has also been conjugated to different nanocarriers to improve the specificity of the delivery system and it has been shown that a nanocomplex system between the positively charged TRAIL and the negatively charged chondroitin sulfate (CS) (CS/TRAIL) was designed and applied in poly (lactide-co-glycolide) (PLGA) microspheres (MSs). The results indicated that TC-loaded PLGA MSs significantly inhibited tumour growth [122]. Furthermore, another recently published work indicated that nanoparticle modified with polyethyleneimine was applied to be a vector of TRAIL for cervical cancer gene therapy [123].

TRAIL resistance has been frequently observed in cancer cells and different approaches are being tested to overcome the TRAIL resistant phenotype. There are different subsets of anti-apoptotic proteins which are overexpressed thus inducing resistance against TRAIL. Results have shown that natural flavonoid chrysin inhibited STAT3 phosphorylation thus repressing transcriptional regulation of Mcl-1. Proof of the concept was provided by treating cervical cancer cells with STAT3-specific inhibitor, cucurbitacin-I, which decreased Mcl-1 levels and enhanced TRAIL-induced cell death [124]. Likewise 5, 7-Dihydroxyflavone is a dietary flavonoid has also been reported to overcome resistance against TRAIL by effectively targeting STAT3 phosphorylation. Additionally, Bcl-2, Mcl-1, and IAPs were down-regulated and proapoptotic protein Bax was found to be up-regulated [125]. Equol is an isoflavan produced by intestinal bacteria and has been shown to enhance TRAIL-induced apoptosis of HeLa cells through a death receptor-mediated caspase pathway. Data suggested that Equol enhanced TRAILinduced apoptosis through activation of caspase-3, -8, -9, and cleavage of BID [126].

It is essential to investigate role of HPV encoded proteins in suppressing TRAIL mediated apoptosis. How HPV encoded proteins mediate expression of TRAIL, DR4/DR5 and DcRs is insufficiently studied. It is astonishing to note that HPV16 E2 and E6 are RNA-binding proteins and contain a protein-RNA interaction domain in their C-terminal regions. In addition, E2 and E6 interact with multiple cellular splicing factors like serine/ arginine (SR) proteins [127]. This relationship of HPV encoded proteins with regulators of mRNA splicing needs detailed investigation with reference to TRAIL, DRs and subsets of tumor suppressors. Moreover, impairment of TRAIL mediated apoptosis in HPV infected cancer cells needs additional laboratory based experimentations addressing modes of repression of TRAIL and DR4/DR5 at transcriptional and post-transcriptional level. Do HPV encoded proteins recruit silencing machinery at TRAIL and DR4/5 promoters or is there a miRNA mediated regulation of TRAIL and DR4/DR5 or is there an enhanced degradation of DRs are some questions which demand extensive research. Although some cell type specific studies have revealed that c-Cbl-mediated ubiquitination of TRAIL receptors has a main role in the endosomal sorting leading to the degradative pathway. However none of the studies indicated any relationship between HPV encoded proteins in directing degradation of DRs in cervical cancer cells [128]. However it is clear that HPV encoded proteins use ubiquitin ligases (cullin 1 ubiquitin ligase complex) to degrade tumor suppressors [129]. Membrane-associated RING-CH (MARCH) ubiquitin ligase is also reported to ubiquitinate TRAIL-R1 and impairing its cell surface expression [130].

\section{miRNA and HPV}

Integrative genomics and genetics approaches have proven to be a functional tool in elucidating the complex relationships often found in gene regulatory networks and reconstitution of tumor-suppressive miRNA, or sequence-specific knockdown of oncogenic miRNAs by 'antagomirs', has produced favorable antitumor outcomes in experimental models. We discuss existing knowledge gaps that need to be bridged prior to the consideration of miRNA-based experimental cancer gene therapy. These include our incomplete understanding of ratelimiting cellular components that impact the efficiency of this posttranscriptional gene-silencing phenomenon in HPV expressing cervical cancer cells. We partition this section into regulation of miRNAs by p53 and miRNA subsets which are documented to suppress and promote cervical cancer. We partition this section into regulation of miRNAs by $\mathrm{p} 53$ and miRNA subsets which are documented to suppress and promote cervical cancer.

\section{p53 mediated regulation of miRNA subsets in HPV infected cervical cancer}

It is now clear that HPV encoded proteins target p53 to inhibit apoptosis of host cells. In the next section we discuss subsets of miRNA which are known targets of p53 and are inhibited by degrading p53. Detailed studies suggested that cortisol induced HPV-E6 expression and suppressed p53 and miR-145 in cervical cancer cells. MiR-145 expression in cervical cancer cells was wildtype p53-dependent, and cortisol down-regulated miR145 expression [131]. miR-23b and miR-34a were also known targets of P53 however HPV encoded proteins repressed the expression of miR-23b by degrading $\mathrm{p} 53$ [80-83,132]. Figure 4. miR-15a/miR-16/miR195/miR-497 family, miR-143/miR-145 and the miR-106-363 cluster appeared to be misrepresented in HPV positive cervical cancer cells [133]. HPV encoded proteins regulate expression of miRNAs in infected cells and Figure 4 illustrates the mechanisms. 


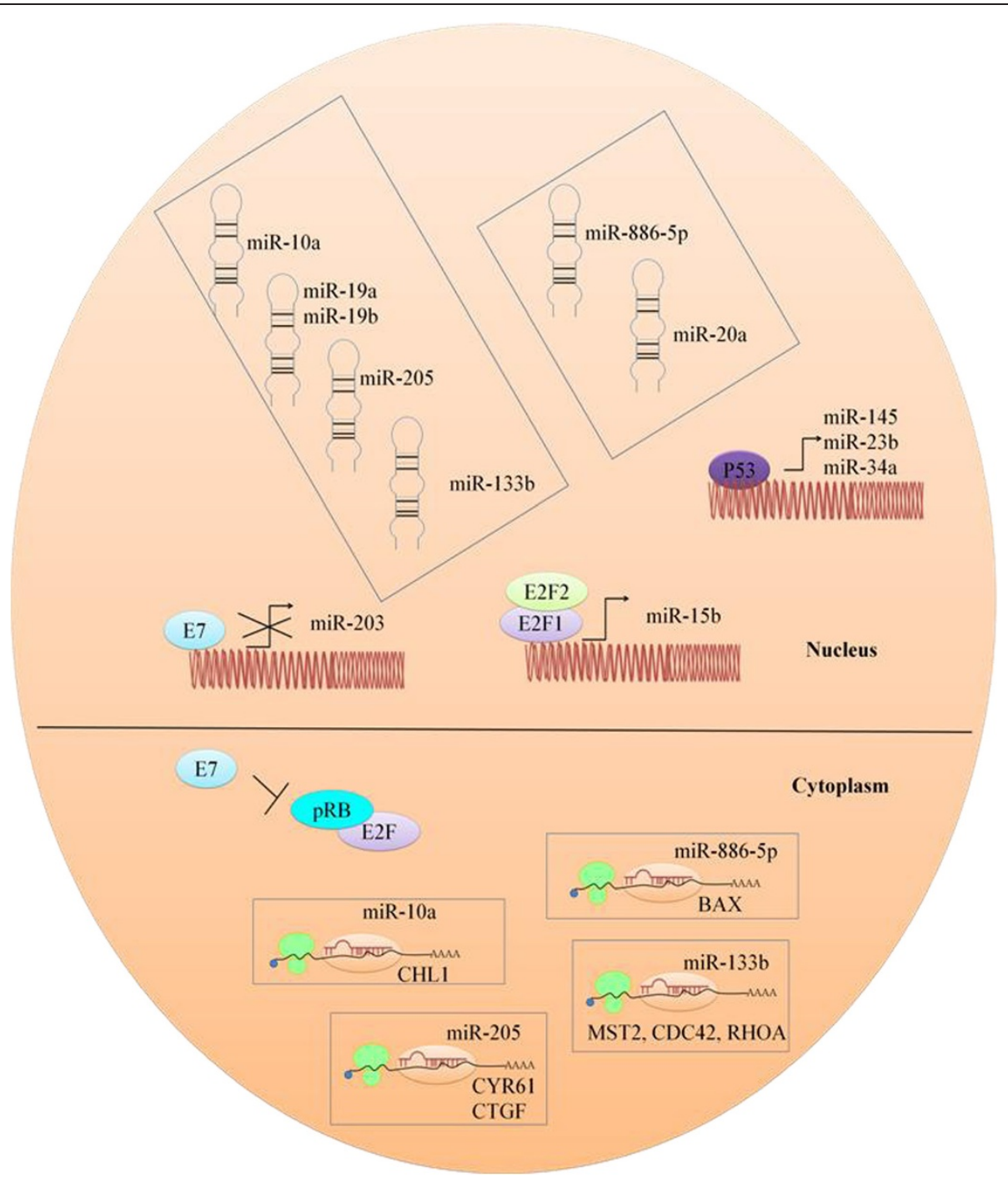

Figure 4 Shows E7 mediated inhibition of pRB that results in sequestration of E2F. E2F moves into the nucleus to stimulate the expression of miR-15b. E7 also directly represses miR-203 expression. Additionally, p53 triggers expression of miR-145, miR-23b and miR-34a. Therefore E7 indirectly repress the expression of target miRNAs by degrading p53. miRNAs in slanting boxes are over-expressed in cervical cancer cells. Rectangular Boxes indicate post-transcriptional processing of gene subsets bi miRNAs.

\section{HPV encoded proteins use epigenetic machinery writers of sleeping beauty tale of miRNA}

HPV encoded proteins use methylation machinery to suppress tumor suppressor miRNAs and there is a direct piece of evidence that reveals hypermethylation of miR-124a and miR-203 in the precursor lesions [134]. There is also considerable evidence regarding increased methylation levels of hsa-miR-124-1 and hsa-miR-1242 that strongly correlated with reduced hsa-miR-124 expression in cervical tissue specimens [135]. miR-218 was also found to be downregulated [136]. It appears that tumor suppressor miRNA subsets are repressed by installing co-repressor machinery at the promoter regions.

\section{Tumor suppressor miRNAs}

Phosphoinositide 3-kinase catalytic subunit delta (PIK3CD) is a miR-125b target and cells reconstituted with miR125b represented inhibition of PI3K/Akt/mTOR pathway, while Bid was up-regulated in miR-125b-overexpressing cells [137]. MiR-384-5p is also a known regulator of PIK3CD [138]. MiR-7 has been shown to disrupt PI3K/ Akt/mTOR signaling axis [139]. However precise role of miR-384-5p and miR-7 needs to be determined in HPV expressing cervical cancer cells.

miR-17-5p and miR-143 act as tumor suppressors in cancer cells by targeting TP53INP1 and Bcl-2 respectively [140-142]. Fascinatingly, overexpression of miR-424 repressed the expression of checkpoint kinase 1 (Chk1) and 
substantially inhibited cancer progression [143,144]. miR214 negatively regulates $\mathrm{N}$-acetylgalactosaminyltransferase 7 (GALNT7) and distinctly inhibits cervical cancer cell proliferation, migration, and invasion [145]. miR-372 and miR-223 are down-regulated in cervical cancer and restoration of these miRNAs inhibited cell migration and invasion [146,147]. miR-375 is a tumor suppressor gene and is downregulated in cervical cancer cells however it has been reported that HPV16 E6/E7 does not directly regulate miR-375 expression [80-83,148].

It is noteworthy that transiently transfecting pre-miR$34 c-3 p$, in HPV positive cervical cancer cells caused S-phase arrest and apoptosis [149]. It is worth describing that introduction of expression vectors for miR-203 into HPV positive cells substantially limited HPV amplification. It has also been noted that miR-203 expression is regulated through $\mathrm{MAPK/PKC}$ pathway and interestingly, this pathway is hampered in E7 expressing cells. Pharmacological activation of PKC pathway is speculated to trigger the expression of miR-203 via AP-1, AP-2, and Sp-1 transcription factor families whose binding sites are present in miR-203. Therefore E7 expressing cells treated with PKC activators did not display an increase in expression of miR-203 [150]. E5 expressing cervical cancer cells showed upregulated miR-146a and repressed miR-324-5p [151]. MiR-497 is a tumor suppressor and targets IGF-1R however it is downregulated in cervical cancer cells [152]. It has been shown that cervical cancer cells treated with mTOR inhibitors displayed an increase in expression of miR-143. It was noted that mTOR was involved in repressing the expression of miR-143 [153]. Additional studies are required to dissect the precise pathway downstream to mTOR that represses the expression. Tumor suppressor miRNA subsets are shown in Figure 5.

\section{Oncomirs}

miR-10a, miR-205 and miR-133b are upregulated in cervical cancer and promote migration and invasion [154-156]. CYR61 and CTGF are members of the cysteine rich 61/

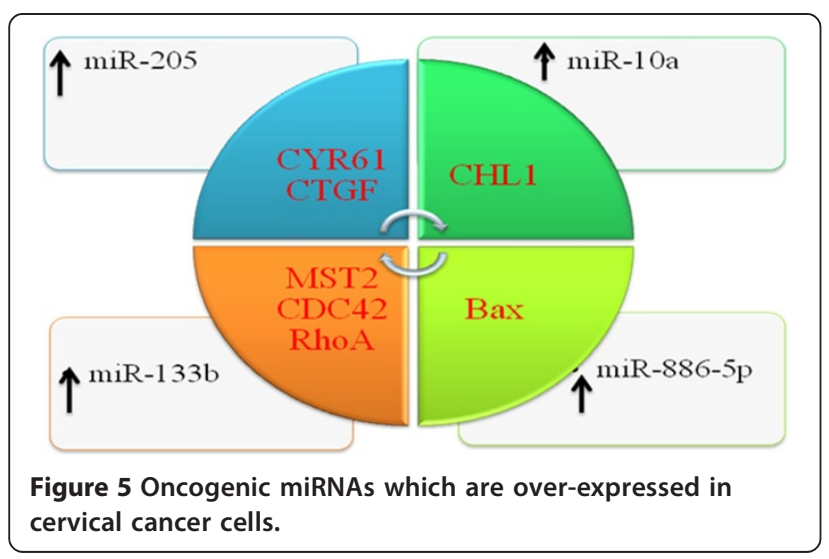

connective tissue growth factor/nephroblastoma (CCN) family of growth regulators and have tumor suppressing properties. However targeting of CYR61 and CTGF by miR-205 promotes cellular proliferation [155]. CHL1 gene - close homolog of L1, also known as CALL - cell adhesion L1-like encodes a one-pass trans-membrane cell adhesion molecule (CAM) capable of both homotypic and heterotypic binding and has tumor suppressing properties. It is negatively controlled by miR-10a [154]. miR-133b enhances cell proliferation via negative regulation of mammalian sterile 20-like kinase 2 (MST2), cell division control protein 42 homolog (CDC42) and ras homolog gene family member A (RHOA). Additionally, miR-133b overexpressing cells have activated AKT1 and ERK1/2 [156]. Up-regulation of miR-19a and miR-19b promoted cell growth and invasion. The Cullin family member of RING E3 ubiquitin ligases (CUL5) is negatively regulated. Cullin-RING E3 ubiquitin ligase are involved in chaperone-mediated protein regulation and act as tumor suppressors. [143,144]. Therefore it is notable that HPV encoded proteins use various strategies to inhibit Cullin 5 mediated degradation of oncoproteins. miR-20a promoted migration and invasion of cervical cancer cells [157]. miR886-5p is overexpressed in cervical cancer cells and impair apoptosis by negatively regulating Bax [158]. E7 protein of HPV binds to $\mathrm{pRB}$, a negative regulator of E2F that results in sequestration of E2F from pRB. Binding sites for E2F1 and E2F3 have been identified in the promoter of miR-15b and targeted inhibition of HPV16-E7 resulted in downregulation of miR-15b in cancer cells [159] Figure 4. It has lately been shown that HPV16-positive cancer cells have a downregulated miR-218. Detailed analysis showed that HPV16-E6 oncoprotein suppressed the expression of miR-218 and rescued Laminin 5 B3 (LAMB3). LAMB3 is negatively regulated by miR-218 and cells reconstituted with LAMB3 displayed enhanced migratory potential [160]. Likewise, methylation-mediated transcriptional repression of hsa-miR-149, -203 and -375 is noted in cervical cancer [161]. miR-182 is an oncomir and inhibition of miR-182 in HeLa xenograft mouse model, resulted in tumor growth regression. Moreover expression of miRNA subsets in cervical cancer cell lines displayed two upregulated (miR-182 and -183) and nine down-regulated (miR-211, 145, 223, 150, 142-5p, 328, 195, 199b, 142-3p) miRNAs [162]. hsa-miR-15a-3p induces apoptosis in cancer cells via negative regulation of Bcl-xL [163]. Similarly, cell reconstructed with miR-214 showed increased expression of Bax, caspase-9, caspase- 8 and caspase-3. Moreover, it has been persuasively revealed that miR-214 is regulated by DNA methylation and histone deacetylation [164]. NDRG2 distinctively enhanced Bcl-2 expression and increased the Bcl-2/Bax ratio, which decreased sensitivity of Hela cells to drug-induced apoptosis. However cancer cells expressing miR-15b and miR-16 demonstrated a 
down-regulated Bcl-2. It is still not know how NDRG2 knock down stimulates the expression of miR-15b and miR-16 [141,142]. Moreover a cell-type specific study indicates that NDRG2 is negatively regulated by miR-650 [165]. Oncogenic miRNA subsets are shown in Figure 6.

There is a complicated network by which miRNA subsets are transcriptionally triggered by downstream effectors of various signaling cascades and in turn miRNA subsets regulate modulators of signaling cascades. How HPV encoded proteins reconstitute signaling, transcriptional and epigenetic machinery to regulate tumor suppressor miRNAs and oncomirs still is a mystery.

\section{Cervical cancer therapy}

On a similar note, Arsenic trioxide induced cervical cancer apoptosis by downregulating HPV-E6 and upregulating p53 [166]. There is a progressive increase in improving the RNA interference strategies. In line with this approach, it has recently been explored that chitosan is appropriate as a carrier for delivery of siRNA into cancer and delivery of chitosan/HPV16 E7 siRNA nanoparticles in vivo is an effective therapy for cervical cancer [167]. E6/E7 specific siRNA-induced transcriptional gene silencing has recently been effectivley tested in cervical cancer cells [168]. Chloroform Extract of Rasagenthi Mezhugu, induced DNA damage and apoptosis in cervical cancer cells [169]. More interestingly, anti-DR5 monoclonal antibody, MD5-1 with a DNA vaccine encoding calreticulin (CRT) linked to human papillomavirus type 16 (HPV-16) E7 antigen (CRT/E7(detox)) provided unique opportunities for the development of therapeutic strategies. The study revealed biological functionality and highlighted that administration of CRT/E7(detox) in mice bearing the E7-expressing tumor, generated the most potent therapeutic anti-tumor effects as well as highest levels of E7-specific CD8+ T cells [170]. There is a finding that has demonstrated a correlation between the shrinkage of HPV16 E6 and E7+ tumors versus $\mathrm{DC}$ and $\mathrm{LC}$ infiltration in a murine model

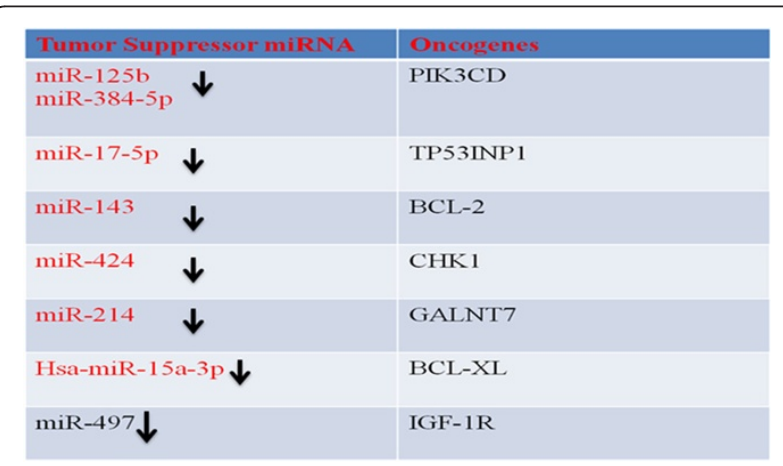

Figure 6 Tumor suppressor miRNAs which are under-expressed in cervical cancer cells. of cervical cancer thus adding new evidence of the preclinical efficacy of Dendritic cells (DCs) and Langerhans cells (LCs) mediated killing. There is also sufficient evidence that suggests that expression of TRAIL decoy receptors is reduced following introduction of E6 and E7 into host cells [171]. Using different in-vitro strategies, E6 and E7 proteins are targeted to suppress carcinogenesis. These targeted approaches included treatment of cervical cancer cells with biflavonoid amentoflavone, curcumin and Ruthenium oligonucleotides. Cervical cancer cells treated with hesperetin (flavonoid from citrus fruits) displayed an upregulated Fas death receptor and its adaptor protein FADD. Additionally, there was an increased expression of different caspases, p53 and Bax Alshatwi et al, [172].

It was shown that targeted inhibition of E6 and E7 resulted in rescue of p53 Lee et al. [173], Maher et al. [174], Reschner et al. [175]. Moreover, delivery of monoclonal antibodies against E6 in transformed cervical keratinocytes has also been tested. There was an enhanced p53 activity after targeting of E6 Togtema et al. [176]. It needs to be pursued with reference to miRNA subsets which are influenced after treatment with antibodies against E6. Future studies must converge on additional natural compounds with minimal off target effects and considerable efficacy.

GRIM-19 has been acclaimed as tumor suppressor as cells reconstituted with GRIM-19 displayed ubiquitination and degradation of E6AP, and disrupted the E6/ E6AP complex. The abrogation of E6/E6AP complex protected p53 from degradation and promoted cell apoptosis [177]. It is impelling to note that phenomenal strides have been made in identifying regulators of cervical cancer. A better understanding of positive and negative regulators will enable the scientists to effectively target oncogenes that promote HPV expression. In line with this approach, it has recently been identified that interaction of mixed lineage leukemia 5 gene (MLL5 $\beta$ ) with the AP-1-binding site at the distal region of the HPV18 long control region led to activation of E6/E7 transcription. Targeted inhibition of MLL5 $\beta$ drastically repressed both E6 and E7 expression [178].

In line with this approach, it has been proved that HPV E2 is negative transcriptional modulator of HPV E6 and E7 oncogenes, and also an apoptosis-inducing agent. There is an increasing trend of transiently transfecting tumor suppressor genes into cancer cells to enhance the efficacy of chemotherapy and radiations. A recent report indicated that oncolytic adenovirus armed with human papillomavirus E2 gene in combination with radiation demonstrated considerably augmented antitumor efficacy [80-83]. Similarly, pretreatment with dihydrotanshinone increased radiation induced apoptosis in cervical cancer cells through down-regulated HPV E6 
gene expression [179]. It has lately been explored that pentoxifylline sensitized human cervical tumor cells to cisplatin-induced apoptosis by inhibiting NF-kappa B and anti-apoptotic proteins [180]. Transgenic mouse model has been developed with malignant cervical lesions allowing the study of the cooperative effect between HPV16-E6/E7 expression and the lack of RXR $\alpha$ in cervical cancer development [181]. This model could be useful to investigate efficacy of chemopreventive and chemotherapeutic strategies. It has been persuasively documented that acetoxychavicol acetate (ACA) with cisplatin (CDDP) worked with effective synergy in HPVpositive human cervical carcinoma cells and induced cell death [182]. HPV encoded proteins control host proteins using an array of post-translational modifications, many of which create binding sites for specific protein-interaction domains thus reconstructing signaling cascades for regulation of cell proliferation. We have discussed common strategies used by HPV encoded proteins for modulation of protein network to impair apoptosis in host cells.

\section{Conclusion}

Signaling networks in cells are composed of upstream and downstream subnetworks. The upstream subnetwork contains the intertwined network of signaling pathways, while the downstream regulatory part controls expression of tumor promoting, tumor suppressing, proapoptotic, anti-apoptotic and microRNA subsets in a context dependent manner. HPV encoded proteins have emerged as centrally positioned hubs in regulation of signaling cascades in cervical cancer. Recent studies have revealed an extraordinarily complex network of proteins that is regulated by HPV encoded proteins. This highly interconnected network contrasts our conventional view of the cervical cancer as a linear sequence of events. It has lately been shown that $\mathrm{Hh}$ signaling is not induced directly by HPV-encoded proteins instead Hh-activating mutations are selected in cells initially immortalized by HPV [183]. Darinaparsin (ZIO-101, S-dimethylarsinoglutathione) is an organic arsenical and has been noted to effectively inhibit Shh-induced Gli1 expression in cervical cancer cells [184]. It seems that we still lack a broader landscape of linear and integrated signaling pathways in HPV infected cervical cancer cells. SHH signaling related information is insufficient and needs detailed investigation. Coordinate regulation of an miRNA network by a signaling pathway may lead to unpredictable effects on proteins when combinatorial effects are considered, and further exploration of the rules for such interactions are needed in HPV expressing cervical cancer cells. It is appropriate to mention that miRNA subsets under-expressed in cervical cancer cells can be used to regulate the proficiency of cancer-specific adenoviral vector that expressed TRAIL based on miRNA response elements (MREs) of miRNAs whose levels were reduced in cervical cancer. Similar approaches have been tested using in bladder cancer and glioma using adenoviral vector expressing TRAIL and introducing MREs of miRNA subsets down-regulated in respective cancer cells $[185,186]$.

Unquestionably, the growing interest in this class of regulatory RNAs will lead to continued classification of miRNA expression particularly in cervical cancer and recognition of novel miRNA subsets that may act as oncogenes and tumour suppressors. Moreover, it is essential to develop a multi-level cross-talk network of the Notch, Wnt, TGF- $\beta$ and SHH pathways, identify mutual and pathway-specific components/regulators and predominantly how HPV encoded proteins mastermind cross-talk between these pathways and other pathways.

\section{Competing interest}

All the authors declare that they do not have any conflict of interest.

\section{Authors' contribution}

TAH and FZ conceived the idea and did literature search on specific points. AAF and TAH did the literature search, integrated different points, and drafted the manuscript. TAH and FZ were involved in discussion and editing the manuscript. AAF designed the diagrams. All authors read and approved the final manuscript.

\section{Author details}

'Department of Obstetrics \& Gynaecology, RLMC, 35 Km Ferozepur Road, Lahore, Pakistan. ${ }^{2}$ Laboratory for Translational oncology and Personalized Medicine, RLMC, 35 Km Ferozepur Road, Lahore, Pakistan.

Received: 17 January 2013 Accepted: 17 May 2013

Published: 17 June 2013

\section{References}

1. Denny L: Cervical cancer: prevention and treatment. Discov Med 2012, 14(75):125-31.

2. Sheinfeld Gorin SN, Glenn BA, Perkins RB: The human papillomavirus (HPV) vaccine and cervical cancer: uptake and next steps. Adv Ther 2011, 28(8):615-39.

3. Zheng ZM, Baker CC: Papillomavirus genome structure, expression, and post-transcriptional regulation. Front Biosci 2006, 11:2286-302.

4. Fehrmann F, Laimins LA: Human papillomaviruses: targeting differentiating epithelial cells for malignant transformation. Oncogene 2003, 22(33):5201-7.

5. Thomas M, Narayan N, Pim D, Tomaić V, Massimi P, Nagasaka K, Kranjec C, Gammoh N, Banks L: Human papillomaviruses, cervical cancer and cell polarity. Oncogene 2008, 27(55):7018-30.

6. Moody CA, Laimins LA: Human papillomavirus oncoproteins: pathways to transformation. Nat Rev Cancer 2010, 10(8):550-60.

7. Horvath CA, Boulet GA, Renoux VM, Delvenne PO, Bogers JP: Mechanisms of cell entry by human papillomaviruses: an overview. Virol J 2010, 7:11. doi:10.1186/1743-422X-7-11.

8. Letian T, Tianyu Z: Cellular receptor binding and entry of human papillomavirus. Virol J 2010, 7:2. doi:10.1186/1743-422X-7-2

9. Surviladze Z, Dziduszko A, Ozbun MA: Essential roles for soluble virion-associated heparan sulfonated proteoglycans and growth factors in human papillomavirus infections. PLOS Pathog 2012, 8(2):e1002519.

10. Scheffer KD, Gawlitza A, Spoden GA, Zhang XA, Lambert C, Berditchevski F, Florin L: Tetraspanin CD151 Mediates Papillomavirus Type 16 Endocytosis. J Virol 2013, 87(6):3435-46. doi:10.1128/JVI.02906-12.

11. Spangle JM, Munger K: The HPV16 E6 Oncoprotein Causes Prolonged Receptor Protein Tyrosine Kinase Signaling and Enhances Internalization of Phosphorylated Receptor Species. PLoS Pathog 2013, 9(3):e1003237. 
12. Abban $C Y$, Meneses PI: Usage of heparan sulfate, integrins, and FAK in HPV16 infection. Virology 2010, 403(1):1-16.

13. Tran T, Barlow B, O'Rear L, Jarvis B, Li Z, Dickeson K, Dupont W, Zutter M: Loss of the a2 $\beta 1$ integrin alters human papilloma virus-induced squamous carcinoma progression in vivo and in vitro. PLoS One 2011, 6(10):e26858.

14. Wilke CM, Hall BK, Hoge A, Paradee W, Smith DI, Glover TW: FRA3B extends over a broad region and contains a spontaneous HPV16 integration site: direct evidence for the coincidence of viral integration sites and fragile sites. Hum Mol Genet 1996, 5(2):187-95.

15. Giarnieri E, Zanesi N, Bottoni A, Alderisio M, Lukic A, Vecchione A, Ziparo V, Croce CM, Mancini R: Oncosuppressor proteins of fragile sites are reduced in cervical cancer. Cancer Lett 2010, 289(1):40-5.

16. Moody CA, Laimins LA: Human papillomaviruses activate the ATM DNA damage pathway for viral genome amplification upon differentiation. PLoS Pathog 2009, 5(10):e1000605.

17. Hsu YL, Chia CC, Chen PJ, Huang SE, Huang SC, Kuo PL: Shallot and licorice constituent isoliquiritigenin arrests cell cycle progression and induces apoptosis through the induction of ATM/p53 and initiation of the mitochondrial system in human cervical carcinoma HeLa cells. Mol Nutr Food Res 2009, 53(7):826-35.

18. Craigo J, Callahan M, Huang RC, DeLucia AL: Inhibition of human papillomavirus type 16 gene expression by nordihydroguaiaretic acid plant lignan derivatives. Antiviral Res 2000, 47(1):19-28.

19. Wetherill LF, Holmes KK, Verow M, Müller M, Howell G, Harris M, Fishwick C, Stonehouse N, Foster R, Blair GE, Griffin S, Macdonald A: High-risk human papillomavirus E5 oncoprotein displays channel-forming activity sensitive to small-molecule inhibitors. J Virol 2012, 86(9):5341-51.

20. Belleudi F, Leone L, Purpura V, Cannella F, Scrofani C, Torrisi MR: HPV16 E5 affects the KGFR/FGFR2b-mediated epithelial growth through alteration of the receptor expression, signaling and endocytic traffic. Oncogene 2011, 30(50):4963-76.

21. Muto V, Stellacci E, Lamberti AG, Perrotti E, Carrabba A, Matera G, Sgarbanti M, Battistini A, Liberto MC, Focà A: Human papillomavirus type 16 E5 protein induces expression of beta interferon through interferon regulatory factor 1 in human keratinocytes. J Virol 2011, 85(10):5070-80.

22. Surviladze Z, Sterk RT, Deharo SA, Ozbun MA: Cellular Entry of Human Papillomavirus Type 16 Involves Activation of the Phosphatidylinositol 3-Kinase/Akt/mTOR Pathway and Inhibition of Autophagy. J Virol 2013, 87(5):2508-17.

23. Cardeal LB, Boccardo E, Termini L, Rabachini T, Andreoli MA, di Loreto C, Longatto Filho A, Villa LL, Maria-Engler SS: HPV16 oncoproteins induce MMPs/RECK-TIMP-2 imbalance in primary keratinocytes: possible implications in cervical carcinogenesis. PLoS One 2012, 7(3):e33585. doi:10.1371/journal.pone.0033585.

24. Fera D, Marmorstein R: Different regions of the HPV-E7 and Ad-E1A viral oncoproteins bind competitively but through distinct mechanisms to the $\mathrm{CH} 1$ transactivation domain of p300. Biochemistry 2012, 51(47):9524-34.

25. Todorovic B, Hung K, Massimi P, Avvakumov N, Dick FA, Shaw GS, Banks L, Mymryk JS: Conserved region 3 of human papillomavirus 16 E7 contributes to deregulation of the retinoblastoma tumor suppressor. J Virol 2012, 86(24):13313-23.

26. Schneider MA, Scheffer KD, Bund T, Boukhallouk F, Lambert C, Cotarelo C, Pflugfelder GO, Florin L, Spoden GA: The Transcription Factors TBX2 and TBX3 interact with HPV16 L2 and repress the Long Control Region of Human Papillomaviruses. J Virol 2013, 87(8):74-4461.

27. Lee D, Kim HZ, Jeong KW, Shim YS, Horikawa I, Barrett JC, Choe J: Human papillomavirus E2 down-regulates the human telomerase reverse transcriptase promoter. J Biol Chem 2002, 277(31):27748-56.

28. Lee DK, Kim BC, Kim IY, Cho EA, Satterwhite DJ, Kim SJ: The human papilloma virus $\mathrm{E7}$ oncoprotein inhibits transforming growth factor-beta signaling by blocking binding of the Smad complex to its target sequence. J Biol Chem 2002, 277(41):38557-64.

29. Ashrafi GH, Haghshenas M, Marchetti B, Campo MS: $E 5$ protein of human papillomavirus 16 downregulates HLA class I and interacts with the heavy chain via its first hydrophobic domain. Int J Cancer 2006, 119:2105-2112.

30. Miura S, Kawana K, Schust DJ, Fujii T, Yokoyama T, I wasawa Y, Nagamatsu T, Adachi K, Tomio A, Tomio K, Kojima S, Yasugi T, Kozuma S, Taketani Y: CD1d, a sentinel molecule bridging innate and adaptive immunity, is downregulated by the human papillomavirus (HPV) E5 protein: a possible mechanism for immune evasion by HPV. J Virol 2010, 84(22):11614-23.
31. On JM, Kim SH, Lee YI, Seo M, Kim SY, Song YS, Kim WH, Juhnn YS: Human papillomavirus E5 protein induces expression of the EP4 subtype of prostaglandin E2 receptor in cyclic AMP response element-dependent pathways in cervical cancer cells. Carcinogenesis 2009, 30(1):141-9.

32. Wang Q, Kennedy A, Das P, Mclntosh PB, Howell SA, Isaacson ER, Hinz SA, Davy C, Doorbar J: Phosphorylation of the human papillomavirus type 16 E1-E4 protein at T57 by ERK triggers a structural change that enhances keratin binding and protein stability. J Virol 2009, 83(8):3668-83.

33. Davy CE, Ayub M, Jackson DJ, Das P, Mclntosh P, Doorbar J: HPV16 E1-E4 protein is phosphorylated by $\mathrm{Cdk2/cyclin} \mathrm{A} \mathrm{and} \mathrm{relocalizes} \mathrm{this} \mathrm{complex}$ to the cytoplasm. Virology 2006, 349(1):230-44.

34. Liao S, Deng D, Hu X, Wang W, Li L, Li W, Zhou J, Xu G, Meng L, Wang S, Ma D: HPV16/18 E5, a promising candidate for cervical cancer vaccines, affects SCPs, cell proliferation and cell cycle, and forms a potential network with E6 and E7. Int J Mol Med 2013, 31(1):120-8.

35. Nuovo GJ, Wu X, Volinia S, Yan F, di Leva G, Chin N, Nicol AF, Jiang J, Otterson G, Schmittgen TD, Croce C: Strong inverse correlation between microRNA-125b and human papillomavirus DNA in productive infection. Diagn Mol Pathol 2010, 19(3):135-43.

36. Bhattacharjya S, Nath S, Ghose J, Maiti GP, Biswas N, Bandyopadhyay S, Panda CK, Bhattacharyya NP, Roychoudhury S: miR-125b promotes cell death by targeting spindle assembly checkpoint gene MAD1 and modulating mitotic progression. Cell Death Differ 2013, 20(3):430-42.

37. McPhillips MG, Veerapraditsin T, Cumming SA, Karali D, Milligan SG, Boner W, Morgan IM, Graham SV: SF2/ASF binds the human papillomavirus type 16 late RNA control element and is regulated during differentiation of virus-infected epithelial cells. J Virol 2004, 78(19):10598-605.

38. Somberg M, Schwartz S: Multiple ASF/SF2 sites in the human papillomavirus type 16 (HPV-16) E4-coding region promote splicing to the most commonly used 3'-splice site on the HPV-16 genome. J Virol 2010, 84(16):8219-30.

39. Rosenberger S, De-Castro Arce J, Langbein L, Steenbergen RD, Rösl F: Alternative splicing of human papillomavirus type-16 E6/E6* early mRNA is coupled to EGF signaling via Erk1/2 activation. Proc Natl Acad Sci USA 2010, 107(15):7006-11.

40. Zhao X, Rush M, Schwartz S: Identification of an hnRNP A1-dependent splicing silencer in the human papillomavirus type $16 \mathrm{~L} 1$ coding region that prevents premature expression of the late L1 gene. J Virol 2004, 78(20):10888-905.

41. Kranjec C, Banks L: A systematic analysis of human papillomavirus (HPV) E6 PDZ substrates identifies MAGI-1 as a major target of HPV type 16 (HPV-16) and HPV-18 whose loss accompanies disruption of tight junctions. J Virol 2011, 85(4):1757-64.

42. Villota C, Campos A, Vidaurre S, Oliveira-Cruz L, Boccardo E, Burzio VA, Varas M, Villegas J, Villa LL, Valenzuela PD, Socías M, Roberts S, Burzio LO: Expression of mitochondrial non-coding RNAs (ncRNAs) is modulated by high risk human papillomavirus (HPV) oncogenes. J Biol Chem 2012, 287(25):21303-15.

43. Gao L, Gu PQ, Fan WM, Liu Z, Qiu F, Peng YZ, Guo XR: The role of gC1qR in regulating survival of human papillomavirus 16 oncogene-transfected cervical cancer cells. Int J Oncol 2011, 39(5):1265-72.

44. Nor Rashid N, Yusof R, Watson RJ: Disruption of repressive p130-DREAM complexes by human papillomavirus $16 \mathrm{E} 6 / \mathrm{E} 7$ oncoproteins is required for cell-cycle progression in cervical cancer cells. J Gen Virol 2011, 92(Pt 11):2620-7.

45. Diaz-Chavez J, Hernandez-Pando R, Lambert PF, Gariglio P: Down-regulation of transforming growth factor-beta type II receptor (TGF-betaRII) protein and mRNA expression in cervical cancer. Mol Cancer 2008, 7:3. doi:10.1186/1476-4598-7-3.

46. Liang F, Kina S, Takemoto H, Matayoshi A, Phonaphonh T, Sunagawa N, Arakaki K, Arasaki A, Kuang H, Sunakawa H: HPV16E6-dependent c-fos expression contributes to AP-1 complex formation in SiHa cells. Mediators Inflamm 2011, 2011:263216.

47. Peralta-Zaragoza O, Bermúdez-Morales V, Gutiérrez-Xicotencatl L, Alcocer-González J, Recillas-Targa F, Madrid-Marina V: E6 and E7 oncoproteins from human papillomavirus type 16 induce activation of human transforming growth factor beta1 promoter throughout Sp1 recognition sequence. Viral Immunol 2006, 19(3):468-80.

48. Xu Q, Wang S, Xi L, Wu S, Chen G, Zhao Y, Wu Y, Ma D: Effects of human papillomavirus type $16 \mathrm{E7}$ protein on the growth of cervical carcinoma cells and immuno-escape through the TGF-beta1 signaling pathway. Gynecol Oncol 2006, 101(1):132-9. 
49. Dey A, Atcha IA, Bagchi S: HPV16 E6 oncoprotein stimulates the transforming growth factor-beta 1 promoter in fibroblasts through a specific GC-rich sequence. Virology 1997, 228(2):190-9

50. Torng PL, Chan WY, Lin CT, Huang SC: Decreased expression of human papillomavirus E2 protein and transforming growth factor-beta1 in human cervical neoplasia as an early marker in carcinogenesis. J Surg Oncol 2003, 84(1):17-23.

51. Deng W, Tsao SW, Kwok YK, Wong E, Huang XR, Liu S, Tsang CM, Ngan HY, Cheung AN, Lan HY, Guan XY, Cheung AL: Transforming growth factor beta1 promotes chromosomal instability in human papillomavirus 16 E6E7-infected cervical epithelial cells. Cancer Res 2008, 68(17):7200-9.

52. Tian Y, Wu P, Luo AY, Xi L, Zhou JF, Ma D: Expression and significance of Smad2/3 and HPV16 E7 in cervical intraepithelial neoplasia and cervical carcinoma. Ai Zheng 2007, 26(9):967-71.

53. Kloth JN, Kenter GG, Spijker HS, Uljee S, Corver WE, Jordanova ES, Fleuren GJ, Gorter A: Expression of Smad2 and Smad4 in cervical cancer: absent nuclear Smad4 expression correlates with poor survival. Mod Pathol 2008, 21(7):866-75.

54. Hariharan R, Babu JM PR, Pillai MR: Mutational analysis of Smad7 in human cervical cancer. Oncol Rep 2009, 21(4):1001-4.

55. Donalisio M, Cornaglia M, Landolfo S, Lembo D: TGF-beta1 and IL-4 downregulate human papillomavirus-16 oncogene expression but have differential effects on the malignant phenotype of cervical carcinoma cells. Virus Res 2008, 132(1-2):253-6.

56. Baldwin A, Pirisi L, Creek KE: NFI-Ski interactions mediate transforming growth factor beta modulation of human papillomavirus type 16 early gene expression. J Virol 2004, 78(8):3953-3964.

57. Shier MK, Neely EB, Ward MG, Meyers C, Howett MK: Transforming growth factor beta 1 (TGF beta 1) down-regulates expression and function of proliferation-inducing molecules in HPV-transformed cells. Anticancer Res 1999, 19(6B):4977-82.

58. Shier MK, Neely EB, Ward MG, Richards ME, Manders EC, Meyers C, Howett MK: Correlation of TGF beta 1 overexpression with down-regulation of proliferation-inducing molecules in HPV-11 transformed human tissue xenografts. Anticancer Res 1999, 19(6B):4969-76.

59. Uren A, Fallen $S$, Yuan H, Usubütün A, Küçükali T, Schlegel R, Toretsky JA Activation of the canonical Wnt pathway during genital keratinocyte transformation: a model for cervical cancer progression. Cancer Res 2005, 65(14):6199-206

60. Rampias T, Boutati E, Pectasides E, Sasaki C, Kountourakis P, Weinberger $P$, Psyrri A: Activation of Wnt signaling pathway by human papillomavirus E6 and E7 oncogenes in HPV16-positive oropharyngeal squamous carcinoma cells. Mol Cancer Res 2010, 8(3):433-43.

61. Bulut G, Fallen S, Beauchamp EM, Drebing LE, Sun J, Berry DL, Kallakury B, Crum CP, Toretsky JA, Schlegel R, Üren A: Beta-catenin accelerates human papilloma virus type-16 mediated cervical carcinogenesis in transgenic mice. PLoS One 2011, 6(11):e27243. doi:10.1371/journal.pone.0027243.

62. van der Meide WF, Snellenberg S, Meijer CJ, Baalbergen A, Helmerhorst TJ, van der Sluis WB, Snijders PJ, Steenbergen RD: Promoter methylation analysis of WNT/ $\beta$-catenin signaling pathway regulators to detect adenocarcinoma or its precursor lesion of the cervix. Gynecol Oncol 2011, 123(1):116-22.

63. Talora C, Cialfi S, Segatto O, Morrone S, Kim Choi J, Frati L, Paolo Dotto G, Gulino A, Screpanti I: Constitutively active Notch1 induces growth arrest of HPV-positive cervical cancer cells via separate signaling pathways. Exp Cell Res 2005, 305(2):343-54.

64. Henken FE, De-Castro Arce J, Rösl F, Bosch L, Meijer CJ, Snijders PJ, Steenbergen RD: The functional role of Notch signaling in HPV-mediated transformation is dose-dependent and linked to AP-1 alterations. Cell Oncol (Dordr). 2012, 35(2):77-84

65. Veeraraghavalu K, Subbaiah VK, Srivastava S, Chakrabarti O, Syal R, Krishna S: Complementation of human papillomavirus type 16 E6 and E7 by Jagged 1-specific Notch1-phosphatidylinositol 3-kinase signaling involves pleiotropic oncogenic functions independent of CBF1;Su(H);Lag-1 activation. J Virol 2005, 79(12):7889-98.

66. Veeraraghavalu K, Pett M, Kumar RV, Nair P, Rangarajan A, Stanley MA, Krishna S: Papillomavirus-mediated neoplastic progression is associated with reciprocal changes in JAGGED1 and manic fringe expression linked to notch activation. J Virol 2004, 78(16):8687-700.

67. Weijzen S, Zlobin A, Braid M, Miele L, Kast WM: HPV16 E6 and E7 oncoproteins regulate Notch-1 expression and cooperate to induce transformation. J Cell Physiol 2003, 194(3):356-62.
68. Munagala R, Kausar H, Munjal C, Gupta RC: Withaferin A induces p53dependent apoptosis by repression of HPV oncogenes and upregulation of tumor suppressor proteins in human cervical cancer cells. Carcinogenesis 2011, 32(11):1697-705.

69. Zhang G, Liu Y, Yu L, Sun L: GFP/HPV-16E6 fusion protein induces apoptosis in MCF-7 and 293T cells using a transient expression system. Oncol Rep 2012, 28(5):1673-80.

70. Mahata S, Maru S, Shukla S, Pandey A, Mugesh G, Das BC, Bharti AC: Anticancer property of Bryophyllum pinnata (Lam.) Oken. leaf on human cervical cancer cells. BMC Complement Altern Med 2012, 12:15.

71. Preethy CP, Padmapriya R, Periasamy VS, Riyasdeen A, Srinag S, Krishnamurthy $\mathrm{H}$, Alshatwi AA, Akbarsha MA: Antiproliferative property of $\mathrm{n}$-hexane and chloroform extracts of Anisomeles malabarica (L). R. Br. in HPV16-positive human cervical cancer cells. J Pharmacol Pharmacother. 2012, 3(1):26-34

72. Hellwig CT, Rehm M: TRAIL signaling and synergy mechanisms used in TRAIL-based combination therapies. Mol Cancer Ther 2012, 11(1):3-13.

73. Fulda S: Histone deacetylase (HDAC) inhibitors and regulation of TRAlL-induced apoptosis. Exp Cell Res 2012, 318(11):1208-12.

74. Lin Z, Bazzaro M, Wang MC, Chan KC, Peng S, Roden RB: Combination of proteasome and HDAC inhibitors for uterine cervical cancer treatment. Clin Cancer Res 2009, 15(2):570-7.

75. Darvas K, Rosenberger S, Brenner D, Fritsch C, Gmelin N, Krammer PH, Rösl F: Histone deacetylase inhibitor-induced sensitization to TNFalpha/ TRAIL-mediated apoptosis in cervical carcinoma cells is dependent on HPV oncogene expression. Int J Cancer 2010, 127(6):1384-92.

76. Eaton S, Wiktor P, Thirstrup D, Lake D, Nagaraj VJ: Efficacy of TRAIL treatment against HPV16 infected cervical cancer cells undergoing senescence following siRNA knockdown of E6/E7 genes. Biochem Biophys Res Commun 2011, 405(1):1-6.

77. Reiser J, Hurst J, Voges M, Krauss P, Münch P, Iftner T, Stubenrauch F: High-risk human papillomaviruses repress constitutive kappa interferon transcription via E6 to prevent pathogen recognition receptor and antiviral-gene expression. J Virol 2011, 85(21):11372-80.

78. Martinez-Velazquez M, Melendez-Zajgla J, Maldonado V: Apoptosis induced by cAMP requires Smac/DIABLO transcriptional upregulation. Cell Signal 2007, 19(6):1212-20.

79. Xie W, Jiang $P$, Miao L, Zhao $Y$, Zhimin Z, Qing L, Zhu WG, Wu M: Novel link between E2F1 and Smac/DIABLO: proapoptotic Smac/DIABLO is transcriptionally upregulated by E2F1. Nucleic Acids Res 2006, 34(7):2046-55

80. Wang F, Li Y, Zhou J, Xu J, Peng C, Ye F, Shen Y, Lu W, Wan X, Xie X: miR375 is down-regulated in squamous cervical cancer and inhibits cell migration and invasion via targeting transcription factor SP1. Am J Pathol 2011, 179(5):2580-8.

81. Wang W, Fang Y, Sima N, Li Y, Li W, Li L, Han L, Liao S, Han Z, Gao Q, Li K, Deng D, Meng L, Zhou J, Wang S, Ma D: Triggering of death receptor apoptotic signaling by human papillomavirus 16 E2 protein in cervical cancer cell lines is mediated by interaction with c-FLIP. Apoptosis 2011, 16(1):55-66.

82. Wang W, Xia X, Wang S, Sima N, Li Y, Han Z, Gao Q, Luo A, Li K, Meng L, Zhou J, Wang C, Shen K, Ma D: Oncolytic adenovirus armed with human papillomavirus E2 gene in combination with radiation demonstrates synergistic enhancements of antitumor efficacy. Cancer Gene Ther 2011, 18(11):825-36

83. Wang X, Meyers C, Guo M, Zheng ZM: Upregulation of p18Ink4c expression by oncogenic HPV E6 via p53-miR-34a pathway. Int J Cancer 2011, 129(6):1362-72.

84. Vogt M, Butz K, Dymalla S, Semzow J, Hoppe-Seyler F: Inhibition of Bax activity is crucial for the antiapoptotic function of the human papillomavirus E6 oncoprotein. Oncogene 2006, 25(29):4009-15. Epub 2006 Feb 6.

85. Khan S, Chib R, Shah BA, Wani ZA, Dhar N, Mondhe DM, Lattoo S, Jain SK, Taneja SC, Singh JA: Cyano analogue of boswellic acid induces crosstalk between p53/PUMA/Bax and telomerase that stages the human papillomavirus type 18 positive HeLa cells to apoptotic death. Eur J Pharmacol 2011, 660(2-3):241-8. doi:10.1016/j.ejphar.2011.03.013. Epub 2011 Apr 2.

86. Guo C, Liu K, Zheng Y, Luo H, Chen H, Huang L: Apoptosis induced by an antagonist peptide against HPV16 E7 in vitro and in vivo via restoration of p53. Apoptosis 2011, 16(6):606-18. doi:10.1007/s10495-011-0594-0.

87. Guo CP, Liu KW, Luo HB, Chen HB, Zheng Y, Sun SN, Zhang Q, Huang L: Potent Anti-Tumor Effect Generated by a Novel Human Papillomavirus (HPV) Antagonist Peptide Reactivating the pRb/E2F Pathway. PLoS One 2011, 6(3):e17734. doi:10.1371/journal.pone.0017734. 
88. Zhao CY, Szekely L, Bao W, Selivanova G: Rescue of p53 function by small-molecule RITA in cervical carcinoma by blocking E6-mediated degradation. Cancer Res 2010, 70(8):3372-81. doi:10.1158/0008-5472. CAN-09-2787.

89. Hershko T, Ginsberg D: Up-regulation of $\mathrm{Bcl}-2$ homology $3(\mathrm{BH} 3)$-only proteins by E2F1 mediates apoptosis. J Biol Chem 2004, 279(10):8627-34

90. Tan S, Hougardy BM, Meersma GJ, Schaap B, de Vries EG, van der Zee AG, de Jong S: Human papilloma virus 16 E6 RNA interference enhances cisplatin and death receptor-mediated apoptosis in human cervical carcinoma cells. Mol Pharmacol 2012, 81(5):701-9.

91. Guan B, Yue P, Clayman GL, Sun SY: Evidence that the death receptor DR4 is a DNA damage-inducible, p53-regulated gene. J Cell Physiol 2001, 188(1):98-105.

92. Kabsch K, Mossadegh N, Kohl A, Komposch G, Schenkel J, Alonso A, Tomakidi $P$ : The HPV-16 E5 protein inhibits TRAIL- and FasL-mediated apoptosis in human keratinocyte raft cultures. Intervirology 2004, 47(1):48-56.

93. Vannucchi S, Chiantore MV, Fiorucci G, Percario ZA, Leone S, Affabris E, Romeo G: TRAIL is a key target in S-phase slowing-dependent apoptosis induced by interferon-beta in cervical carcinoma cells. Oncogene 2005, 24(15):2536-46.

94. Garnett TO, Filippova M, Duerksen-Hughes PJ: Accelerated degradation of FADD and procaspase 8 in cells expressing human papilloma virus 16 E6 impairs TRAIL-mediated apoptosis. Cell Death Differ 2006, 13(11):1915-26.

95. Saitoh T, Hirai M, Katoh M: Molecular cloning and characterization of human Frizzled-8 gene on chromosome 10p11.2. Int J Oncol 2001, 18(5):991-6.

96. Yin S, Xu L, Bonfil RD, Banerjee S, Sarkar FH, Sethi S, Reddy KB: Tumor Initiating Cells and FZD8 play a major role in drug resistance in Triple- Negative Breast Cancer. Mol Cancer Ther 2013, 12(4):8-491.

97. He F, Wang Q, Zheng XL, Yan JQ, Yang L, Sun H, Hu LN, Lin Y, Wang X: Wogonin potentiates cisplatin-induced cancer cell apoptosis through accumulation of intracellular reactive oxygen species. Oncol Rep 2012, 28(2):601-5.

98. Bruning A, Vogel M, Mylonas I, Friese K, Burges A: Bortezomib targets the caspase-like proteasome activity in cervical cancer cells, triggering apoptosis that can be enhanced by nelfinavir. Curr Cancer Drug Targets 2011, 11(7):799-809.

99. Im SR, Jang YJ: Aspirin enhances TRAIL-induced apoptosis via regulation of ERK1/2 activation in human cervical cancer cells. Biochem Biophys Res Commun 2012, 424(1):65-70.

100. Goncharenko-Khaider N, Matte I, Lane D, Rancourt C, Piché A: Ovarian cancer ascites increase $\mathrm{Mcl}-1$ expression in tumor cells through ERK1/2 Elk-1 signaling to attenuate TRAlL-induced apoptosis. Mol Cancer 2012, 11:84. doi:10.1186/1476-4598-11-84.

101. Thanaketpaisarn O, Waiwut $P$, Sakurai H, Saiki I: Artesunate enhances TRAIL-induced apoptosis in human cervical carcinoma cells through inhibition of the NF-KB and PI3K/Akt signaling pathways. Int J Oncol 2011, 39(1):279-85

102. Hougardy BM, Reesink-Peters N, van den Heuvel FA, ten Hoor KA, Hollema $H$, de Vries EG, de Jong S, van der Zee AG: A robust ex vivo model for evaluation of induction of apoptosis by rhTRAIL in combination with proteasome inhibitor MG132 in human premalignant cervical explants. Int J Cancer 2008, 123(6):1457-65.

103. Horinaka M, Yoshida T, Shiraishi T, Nakata S, Wakada M, Nakanishi R, Nishino $H$, Sakai T: The combination of TRAIL and luteolin enhances apoptosis in human cervical cancer HeLa cells. Biochem Biophys Res Commun 2005, 333(3):833-8.

104. Huong le D, Shim JH, Choi KH, Shin JA, Choi ES, Kim HS, Lee SJ, Kim SJ, Cho NP, Cho SD: Effect of $\beta$-phenylethyl isothiocyanate from cruciferous vegetables on growth inhibition and apoptosis of cervical cancer cells through the induction of death receptors 4 and 5. J Agric Food Chem 2011, 59(15):8124-31.

105. Eum DY, Byun JY, Yoon CH, Seo WD, Park KH, Lee JH, Chung HY, An S, Suh Y, Kim MJ, Lee SJ: Triterpenoid pristimerin synergizes with taxol to induce cervical cancer cell death through reactive oxygen speciesmediated mitochondrial dysfunction. Anticancer Drugs 2011, 22(8):763-73.

106. Kendrick JE, Straughn JM Jr, Oliver PG, Wang W, Nan L, Grizzle WE, Stockard CR, Alvarez RD, Buchsbaum DJ: Anti-tumor activity of the TRA-8 anti-DR5 antibody in combination with cisplatin in an ex vivo human cervical cancer model. Gynecol Oncol 2008, 108(3):591-7.

107. Maduro JH, de Vries EG, Meersma GJ, Hougardy BM, van der Zee AG, de Jong S: Targeting pro-apoptotic trail receptors sensitizes HeLa cervical cancer cells to irradiation-induced apoptosis. Int J Radiat Oncol Biol Phys 2008, 72(2):543-52.
108. Hougardy BM, Maduro JH, van der Zee AG, de Groot DJ, van den Heuvel FA, de Vries EG, de Jong S: Proteasome inhibitor MG132 sensitizes HPV-positive human cervical cancer cells to rhTRAIL-induced apoptosis. Int J Cancer 2006, 118(8):1892-900.

109. VanOosten RL, Moore JM, Karacay B, Griffith TS: Histone deacetylase inhibitors modulate renal cell carcinoma sensitivity to TRAIL/Apo-2Linduced apoptosis by enhancing TRAIL-R2 expression. Cancer Biol Ther 2005, 4(10):1104-12.

110. Lin T, Ding Z, Li N, Xu J, Luo G, Liu J, Shen J: 2-Tellurium-bridged $\beta$-cyclodextrin, a thioredoxin reductase inhibitor, sensitizes human breast cancer cells to TRAlL-induced apoptosis through DR5 induction and NF-kB suppression. Carcinogenesis 2011, 32(2):154-67.

111. Xu J, Zhou JY, Wei WZ, Philipsen S, Wu GS: Sp1-mediated TRAIL induction in chemosensitization. Cancer Res 2008, 68(16):6718-26.

112. Moon DO, Kim MO, Choi YH, Kim GY: Butein sensitizes human hepatoma cells to TRAIL-induced apoptosis via extracellular signal-regulated kinase/Sp1-dependent DR5 upregulation and NF-kappaB inactivation. Mol Cancer Ther 2010, 9(6):1583-95.

113. Soncini M, Santoro F, Gutierrez A, Frigè G, Romanenghi M, Botrugno OA, Pallavicini I, Pelicci P, Di Croce L, Minucci S: The DNA demethylating agent decitabine activates the TRAIL pathway and induces apoptosis in acute myeloid leukemia. Biochim Biophys Acta 2013, 1832(1):114-20.

114. Benoit YD, Laursen KB, Witherspoon MS, Lipkin SM, Gudas LJ: Inhibition of PRC2 histone methyltransferase activity increases TRAIL-mediated apoptosis sensitivity in human colon cancer cells. J Cell Physiol 2013, 228(4):764-72.

115. Laurson J, Khan S, Chung R, Cross K, Raj K: Epigenetic repression of E-cadherin by human papillomavirus 16 E7 protein. Carcinogenesis 2010, 31(5):918-26.

116. D'Costa ZJ, Jolly C, Androphy EJ, Mercer A, Matthews CM, Hibma MH: Transcriptional repression of E-cadherin by human papillomavirus type 16 E6. PLoS One 2012, 7(11):e48954.

117. Yadav VR, Prasad S, Aggarwal BB: Cardamonin sensitizes tumour cells to TRAIL through ROS- and CHOP-mediated up-regulation of death receptors and down-regulation of survival proteins. Br J Pharmacol 2012, 165(3):741-53.

118. Mendoza FJ, Ishdorj G, Hu X, Gibson SB: Death receptor-4 (DR4) expression is regulated by transcription factor NF-kappaB in response to etoposide treatment. Apoptosis 2008, 13(6):756-70.

119. Liu X, Yue P, Khuri FR, Sun SY: p53 upregulates death receptor 4 expression through an intronic p53 binding site. Cancer Res 2004, 64(15):5078-83.

120. Shetty S, Graham BA, Brown JG, Hu X, Vegh-Yarema N, Harding G, Paul JT, Gibson SB: Transcription factor NF-kappaB differentially regulates death receptor 5 expression involving histone deacetylase 1. Mol Cell Biol 2005, 25(13):5404-16.

121. Ramesh $E$, Alshatwi AA: Naringin induces death receptor and mitochondria-mediated apoptosis in human cervical cancer ( $\mathrm{SiHa}$ ) cells. Food Chem Toxicol 2013, 51:97-105.

122. Kim H, Jeong D, Kang HE, Lee KC: Na KA sulfate polysaccharide/TNFrelated apoptosis-inducing ligand (TRAIL) complex for the long-term delivery of TRAIL in poly(lactic-co-glycolic acid) (PLGA) microspheres. J Pharm Pharmacol 2013, 65(1):11-21.

123. Zheng Y, Chen H, Zeng X, Liu Z, Xiao X, Zhu Y, Gu D, Mei L: Surface modification of TPGS-b-(PCL-ran-PGA) nanoparticles with polyethyleneimine as a co-delivery system of TRAIL and endostatin for cervical cancer gene therapy. Nanoscale Res Lett 2013, 8(1):161.

124. Lirdprapamongkol K, Sakurai H, Abdelhamed S, Yokoyama S, Athikomkulchai S, Viriyaroj A, Awale S, Ruchirawat S, Svasti J, Saiki I: Chrysin overcomes TRAIL resistance of cancer cells through $\mathrm{Mcl}-1$ downregulation by inhibiting STAT3 phosphorylation. Int J Oncol 2013. doi:10.3892/ijo.2013.1926.

125. Zhang Z, Ye T, Cai X, Yang J, Lu W, Hu C, Wang Z, Wang X, Cao P: 5 , 7-Dihydroxyflavone Enhances the Apoptosis-Inducing Potential of TRAIL in Human Tumor Cells via Regulation of Apoptosis-Related Proteins. Evid Based Complement Alternat Med. 2013, 2013:434709.

126. Kim EY, Kim AK: Combination effect of equol and TRAIL against human cervical cancer cells. Anticancer Res 2013, 33(3):903-12.

127. Bodaghi S, Jia R, Zheng ZM: Human papillomavirus type 16 E2 and E6 are RNA-binding proteins and inhibit in vitro splicing of pre-mRNAs with suboptimal splice sites. Virology 2009, 386(1):32-43.

128. Song JJ, Szczepanski MJ, Kim SY, Kim JH, An JY, Kwon YT, Alcala MA Jr, Bartlett DL, Lee YJ: c-Cbl-mediated degradation of TRAIL receptors is responsible for the development of the early phase of TRAIL resistance. Cell Signal 2010, 22(3):553-63. 
129. Huh K, Zhou X, Hayakawa H, Cho JY, Libermann TA, Jin J, Harper JW, Munger K: Human papillomavirus type 16 E7 oncoprotein associates with the cullin 2 ubiquitin ligase complex, which contributes to degradation of the retinoblastoma tumor suppressor. J Virol 2007, 81(18):9737-47.

130. van de Kooij B, Verbrugge I, de Vries E, Gijsen M, Montserrat V, Maas C, Neefjes J, Borst J: Ubiquitination by the membrane-associated RING-CH-8 (MARCH-8) ligase controls steady-state cell surface expression of the death receptor TRAIL-R1. J Biol Chem 2013, 2889(9):28-6617.

131. Shi M, Du L, Liu D, Qian L, Hu M, Yu M, Yang Z, Zhao M, Chen C, Guo L, Wang L, Song L, Ma Y, Guo N: Glucocorticoid regulation of a novel HPV-E6-p53-miR-145 pathway modulates invasion and therapy resistance of cervical cancer cells. J Pathol 2012, 228(2):148-57. doi:10.1002/path.3997.

132. Au Yeung $\mathrm{CL}$, Tsang TY, Yau PL, Kwok TT: Human papillomavirus type 16 E6 induces cervical cancer cell migration through the p53/microRNA23b/urokinase-type plasminogen activator pathway. Oncogene 2011, 30(21):2401-2410.

133. Lajer CB, Garnæs E, Friis-Hansen L, Norrild B, Therkildsen MH, Glud M, Rossing M, Lajer H, Svane D, Skotte L, Specht L, Buchwald C, Nielsen FC: The role of miRNAs in human papilloma virus (HPV)-associated cancers: bridging between HPV-related head and neck cancer and cervical cancer. Br J Cancer 2012, 106(9):1526-34.

134. Botezatu A, Goia-Rusanu CD, lancu IV, Huica I, Plesa A, Socolov D, Ungureanu C, Anton G: Quantitative analysis of the relationship between microRNA-124a, -34b and -203 gene methylation and cervical oncogenesis. Mol Med Report. 2011, 4(1):121-8.

135. Wilting SM, van Boerdonk RA, Henken FE, Meijer CJ, Diosdado B, Meijer GA le Sage C, Agami R, Snijders PJ, Steenbergen RD: Methylation-mediated silencing and tumour suppressive function of hsa-miR-124 in cervical cancer. Mol Cancer 2010, 9:167.

136. Li Y, Liu J, Yuan C, Cui B, Zou X, Qiao Y: High-risk human papillomavirus reduces the expression of microRNA-218 in women with cervical intraepithelial neoplasia. J Int Med Res 2010, 38(5):1730-6.

137. Cui F, Li X, Zhu X, Huang L, Huang Y, Mao C, Yan Q, Zhu J, Zhao W, Shi H: MiR-125b Inhibits Tumor Growth and Promotes Apoptosis of Cervical Cancer Cells by Targeting Phosphoinositide 3-Kinase Catalytic Subunit Delta. Cell Physiol Biochem 2012, 30(5):1310-1318.

138. Bao Y, Lin C, Ren J, Liu J: MicroRNA-384-5p regulates ischemia-induced cardioprotection by targeting phosphatidylinositol-4,5-bisphosphate 3-kinase, catalytic subunit delta (PI3K p1108). Apoptosis 2013.

139. Fang Y, Xue JL, Shen Q, Chen J, Tian L: MicroRNA-7 inhibits tumor growth and metastasis by targeting the phosphoinositide 3-kinase/Akt pathway in hepatocellular carcinoma. Hepatology 2012, 55(6):1852-62.

140. Wei Q, Li YX, Liu M, Li X, Tang H: MiR-17-5p targets TP53INP1 and regulates cell proliferation and apoptosis of cervical cancer cells. IUBMB Life 2012, 64(8):697-704.

141. Liu J, Yang L, Zhang J, Zhang J, Chen Y, Li K, Li Y, Li Y, Yao L, Guo G: Knock-down of NDRG2 sensitizes cervical cancer Hela cells to cisplatin through suppressing Bcl-2 expression. BMC Cancer 2012, 12:370.

142. Liu L, Yu X, Guo X, Tian Z, Su M, Long Y, Huang C, Zhou F, Liu M, Wu X, Wang $X:$ miR-143 is downregulated in cervical cancer and promotes apoptosis and inhibits tumor formation by targeting $\mathrm{BCl}-2$. Mol Med. Report 2012, 5(3):753-60.

143. Xu J, Li Y, Wang F, Wang X, Cheng B, Ye F, Xie X, Zhou C, Lu W: Suppressed miR-424 expression via upregulation of target gene Chk1 contributes to the progression of cervical cancer. Oncogene 2012. doi:10.1038/onc.2012.121.

144. Xu XM, Wang XB, Chen MM, Liu T, Li YX, Jia WH, Liu M, Li X, Tang H: MicroRNA-19a and $-19 \mathrm{~b}$ regulate cervical carcinoma cell proliferation and invasion by targeting CUL5. Cancer Lett 2012, 322(2):148-58.

145. Peng RQ, Wan HY, Li HF, Liu M, Li X, Tang H: MicroRNA-214 suppresses growth and invasiveness of cervical cancer cells by targeting UDP-N -acetyl-a-D-galactosamine:polypeptide $\mathrm{N}$-acetylgalactosaminyltransferase 7. J Biol Chem 2012, 287(17):14301-9.

146. Tian RQ, Wang XH, Hou LJ, Jia WH, Yang Q, Li YX, Liu M, Li X, Tang H: MicroRNA-372 is down-regulated and targets cyclin-dependent kinase 2 (CDK2) and cyclin A1 in human cervical cancer, which may contribute to tumorigenesis. J Biol Chem 2011, 286(29):25556-63.

147. Wu L, Li H, Jia CY, Cheng W, Yu M, Peng M, Zhu Y, Zhao Q, Dong YW, Shao K, Wu A, Wu XZ: MicroRNA-223 regulates FOXO1 expression and cell proliferation. FEBS Lett 2012, 586(7):1038-43.
148. Bierkens M, Krijgsman O, Wilting SM, Bosch L, Jaspers A, Meijer GA, Meijer CJ, Snijders PJ, Ylstra B, Steenbergen RD: Focal aberrations indicate EYA2 and hsa-miR-375 as oncogene and tumor suppressor in cervical carcinogenesis. Genes Chromosomes Cancer 2013, 52(1):56-68.

149. López JA, Alvarez-Salas LM: Differential effects of miR-34c-3p and miR-34c $-5 \mathrm{p}$ on $\mathrm{SiHa}$ cells proliferation apoptosis, migration and invasion. Biochem Biophys Res Commun 2011, 409(3):513-9.

150. Melar-New M, Laimins LA: Human papillomaviruses modulate expression of microRNA 203 upon epithelial differentiation to control levels of p63 proteins. J Virol 2010, 84(10):5212-21.

151. Greco D, Kivi N, Qian K, Leivonen SK, Auvinen P, Auvinen E: Human papillomavirus 16 E5 modulates the expression of host microRNAs. PLoS One 2011, 6(7):e21646. doi:10.1371/journal.pone.0021646.

152. Luo $M$, Shen D, Zhou $X$, Chen $X$, Wang W: MicroRNA-497 is a potential prognostic marker in human cervical cancer and functions as a tumor suppressor by targeting the insulin-like growth factor 1 receptor. Surgery 2013, 153(6):47-836.

153. Li S, Li Y, Hu R, Li W, Qiu H, Cai H, Wang S: The mTOR inhibitor AZD8055 inhibits proliferation and glycolysis in cervical cancer cells. Oncol Lett 2013, 5(2):717-721

154. Long MJ, Wu FX, Li P, Liu M, Li X, Tang H: MicroRNA-10a targets CHL1 and promotes cell growth, migration and invasion in human cervical cancer cells. Cancer Lett 2012, 324(2):186-96.

155. Xie H, Zhao Y, Caramuta S, Larsson C, Lui WO: miR-205 expression promotes cell proliferation and migration of human cervical cancer cells. PLoS One 2012, 7(10):e46990.

156. Qin W, Dong P, Ma C, Mitchelson K, Deng T, Zhang L, Sun Y, Feng X, Ding Y, Lu X, He J, Wen H, Cheng J: MicroRNA-133b is a key promoter of cervical carcinoma development through the activation of the ERK and AKT1 pathways. Oncogene 2012, 31(36):4067-75.

157. Kang HW, Wang F, Wei Q, Zhao YF, Liu M, Li X, Tang H: miR-20a promotes migration and invasion by regulating TNKS2 in human cervical cancer cells. FEBS Lett 2012, 586(6):897-904.

158. Li JH, Xiao X, Zhang YN, Wang YM, Feng LM, Wu YM, Zhang YX: MicroRNA miR-886-5p inhibits apoptosis by down-regulating Bax expression in human cervical carcinoma cells. Gynecol Oncol 2011, 120(1):145-51.

159. Myklebust MP, Bruland O, Fluge $\varnothing$, Skarstein A, Balteskard L, Dahl O: MicroRNA-15b is induced with E2F-controlled genes in HPV-related cancer. Br J Cancer 2011, 105(11):1719-25.

160. Shi TY, Chen XJ, Zhu ML, Wang MY, He J, Yu KD, Shao ZM, Sun MH, Zhou XY, Cheng X, Wu X, Wei Q: A pri-miR-218 variant and risk of cervical carcinoma in Chinese women. BMC Cancer 2013, 13(1):19.

161. Wilting SM, Verlaat W, Jaspers A, Makazaji NA, Agami R, Meijer CJ, Snijders PJ, Steenbergen RD: Methylation-mediated transcriptional repression of microRNAs during cervical carcinogenesis. Epigenetics 2013, 16:8(2).

162. Tang T, Wong HK, Gu W, Yu MY, To KF, Wang CC, Wong YF, Cheung TH, Chung TK, Choy KW: MicroRNA-182 plays an onco-miRNA role in cervical cancer. Gynecol Oncol 2013, 129(1):199-208.

163. Druz A, Chen YC, Guha R, Betenbaugh M, Martin SE, Shiloach J: Large-scale screening identifies a novel microRNA, miR-15a-3p, which induces apoptosis in human cancer cell lines. RNA Biol 2013, 25:10(2).

164. Wang F, Liu M, Li X, Tang H: MiR-214 reduces cell survival and enhances cisplatin-induced cytotoxicity via down-regulation of $\mathrm{Bc} / 2 \mathrm{l} 2$ in cervical cancer cells. FEBS Lett 2013, S0014-5793(13)00047-1:S0014-5793(13)00047-1. S0014-5793(13)00047-1.

165. Feng $L, X i e Y$, Zhang $H$, Wu Y: Down-regulation of NDRG2 gene expression in human colorectal cancer involves promoter methylation and microRNA-650. Biochem Biophys Res Commun 2011, 406(4):534-8.

166. Wen X, Li D, Zhang Y, Liu S, Ghali L, lles RK: Arsenic trioxide induces cervical cancer apoptosis, but specifically targets human papillomavirus-infected cell populations. Anticancer Drugs 2012, 23(3):280-7.

167. Yang J, Li S, Guo F, Zhang W, Wang Y, Pan Y: Induction of apoptosis by chitosan/HPV16 E7 siRNA complexes in cervical cancer cells. Mol Med Report. 2012. doi:10.3892/mmr.2012.1246.

168. Zhou J, Peng C, Li B, Wang F, Zhou C, Hong D, Ye F, Cheng X, Lü W, Xie X: Transcriptional gene silencing of HPV16 E6/E7 induces growth inhibition via apoptosis in vitro and in vivo. Gynecol Oncol 2012, 124(2):296-302.

169. Riyasdeen A, Periasamy VS, Paul P, Alshatwi AA, Akbarsha MA: Chloroform Extract of Rasagenthi Mezhugu, a Siddha Formulation, as an Evidence-Based Complementary and Alternative Medicine for HPV-Positive Cervical Cancers. Evid Based Complement Alternat Med. 2012, 2012:136527. 
170. Tseng CW, Monie A, Trimble C, Alvarez RD, Huh WK, Buchsbaum DJ, Straughn JM Jr, Wang MC, Yagita H, Hung CF, Wu TC: Combination of treatment with death receptor 5-specific antibody with therapeutic HPV DNA vaccination generates enhanced therapeutic anti-tumor effects. Vaccine 2008, 26(34):4314-9.

171. Le Poole IC, ElMasri WM, Denman CJ, Kroll TM, Bommiasamy H, Lyons Eiben G, Kast WM: Langerhans cells and dendritic cells are cytotoxic towards HPV16 E6 and E7 expressing target cells. Cancer Immunol Immunother 2008 57(6):789-97.

172. Alshatwi AA, Ramesh E, Periasamy VS, Subash-Babu P: The apoptotic effect of hesperetin on human cervical cancer cells is mediated through cell cycle arrest, death receptor, and mitochondrial pathways. Fundam Clin Pharmacol 2012. doi:10.1111/j.1472-8206.2012.01061.X.

173. Lee S, Kim H, Kang JW, Kim JH, Lee DH, Kim MS, Yang Y, Woo ER, Kim YM, Hong J, Yoon DY: The biflavonoid amentoflavone induces apoptosis via suppressing E7 expression, cell cycle arrest at sub- $\mathrm{G}_{1}$ phase, and mitochondria-emanated intrinsic pathways in human cervical cancer cells. J Med Food 2011, 14(7-8):808-16.

174. Maher DM, Bell MC, O'Donnell EA, Gupta BK, Jaggi M, Chauhan SC: Curcumin suppresses human papillomavirus oncoproteins, restores p53, Rb, and PTPN13 proteins and inhibits benzo[a]pyrene-induced upregulation of HPV E7. Mol Carcinog 2011, 50(1):47-57. doi:10.1002/ mc.20695.

175. Reschner A, Bontems S, Le Gac S, Lambermont J, Marcélis L, Defrancq E, Hubert P, Moucheron C, Kirsch-De Mesmaeker A, Raes M, Piette J, Delvenne P: Ruthenium oligonucleotides, targeting HPV16 E6 oncogene, inhibit the growth of cervical cancer cells under illumination by a mechanism involving p53. Gene Ther 2012. 10.1038/gt.2012.54.

176. Togtema M, Pichardo S, Jackson R, Lambert PF, Curiel L, Zehbe I: Sonoporation delivery of monoclonal antibodies against human papillomavirus 16 E6 restores p53 expression in transformed cervical keratinocytes. PLoS One 2012, 7(11):e50730. doi:10.1371/journal. pone.0050730.

177. Zhou Y, Wei Y, Zhu J, Wang Q, Bao L, Ma Y, Chen Y, Feng D, Zhang A, Sun J, Nallar SC, Shen K, Kalvakolanu DV, Xiao W, Ling B: GRIM-19 disrupts E6/ E6AP complex to rescue $\mathrm{p} 53$ and induce apoptosis in cervical cancers. PLoS One 2011, 6(7):e22065

178. Yew CW, Lee P, Chan WK, Lim VK, Tay SK, Tan TM, Deng LW: A novel MLL5 isoform that is essential to activate E6 and E7 transcription in HPV16/18-associated cervical cancers. Cancer Res 2011, 71(21):6696-707.

179. Ye Y, Xu W, Zhong W, Li Y, Wang C: Combination treatment with dihydrotanshinone I and irradiation enhances apoptotic effects in human cervical cancer by HPV E6 down-regulation and caspases activation. Mol Cell Biochem 2012, 363(1-2):191-202.

180. Hernandez-Flores G, Ortiz-Lazareno PC, Lerma-Diaz JM, DominguezRodriguez JR, Jave-Suarez LF, Aguilar-Lemarroy Adel C, de Celis-Carrillo R, del Toro-Arreola S, Castellanos-Esparza YC, Bravo-Cuellar A: Pentoxifylline sensitizes human cervical tumor cells to cisplatin-induced apoptosis by suppressing NF-kappa B and decreased cell senescence. BMC Cancer 2011, 11:483.

181. Ocadiz-Delgado R, Castañeda-Saucedo E, Indra AK, Hernandez-Pando R, Flores-Guizar P, Cruz-Colin JL, Recillas-Targa F, Perez-Ishiwara G, Covarrubias L, Gariglio P: RXRa deletion and E6E7 oncogene expression are sufficient to induce cervical malignant lesions in vivo. Cancer Lett 2012, 317(2):226-36

182. Phuah NH, In LL, Azmi MN, Ibrahim H, Awang K, Nagoor NH: Alterations of MicroRNA Expression Patterns in Human Cervical Carcinoma Cells (Ca Ski) toward 1'S-1'-Acetoxychavicol Acetate and Cisplatin. Reprod Sci 2013, 20(5):78-567.

183. Samarzija I, Beard P: Hedgehog pathway regulators influence cervical cancer cell proliferation, survival and migration. Biochem Biophys Res Commun 2012, 425(1):64-9.

184. Mason TA, Kolobova E, Liu J, Roland JT, Chiang C, Goldenring JR: Darinaparsin is a multivalent chemotherapeutic which induces incomplete stress response with disruption of microtubules and Shh signaling. PLOS One 2011, 6(11):e27699. doi:10.1371/journal. pone.0027699.
185. Zhao Y, Li Y, Wang L, Yang H, Wang Q, Qi H, Li S, Zhou P, Liang P, Wang Q, Li X: microRNA response elements-regulated TRAIL expression shows specific survival-suppressing activity on bladder cancer. J Exp Clin Cancer Res 2013, 32(1):10.

186. Bo Y, Guo G, Yao W: miRNA-mediated tumor specific delivery of TRAIL reduced glioma growth. J Neurooncol 2013, 112(1):27-37.

doi:10.1186/1475-2867-13-61

Cite this article as: Halim et al:: Nip the HPV encoded evil in the cancer bud: HPV reshapes TRAILs and signaling landscapes. Cancer Cell International 2013 13:61.

\section{Submit your next manuscript to BioMed Central and take full advantage of:}

- Convenient online submission

- Thorough peer review

- No space constraints or color figure charges

- Immediate publication on acceptance

- Inclusion in PubMed, CAS, Scopus and Google Scholar

- Research which is freely available for redistribution

Submit your manuscript at www.biomedcentral.com/submit
C) BioMed Central 